\title{
Simulation of the long term fate of water and pollutants, transported from the Dardanelles plume into the North Aegean Sea
}

\author{
Kyriakos I. Kopasakis ${ }^{1}$, Anastasios N. Georgoulas ${ }^{1}$, Panagiotis B. Angelidis ${ }^{1}$, Nikolaos E. \\ Kotsovinos $^{1}$, \\ ${ }^{1}$ Laboratory of Hydraulics and Hydraulic Structures, \\ Democritus University of Thrace, Department of Civil Engineering, V. Sofias 12 \\ GR-67 100 Xanthi, Greece \\ Tel: +302541079322, FAX: +302541079604 \\ kkopasak@civil.duth.gr
}

\begin{abstract}
A numerical simulation of the surface buoyant plume that is formed from the Black Sea brackish water discharge into the North Aegean Sea, through the Dardanelles Straits, has been performed using the ELCOM hydrodynamic model after validation with available field and remote sensing data. Important climatological factors, such as air temperature, relative humidity, wind speed, wind direction, solar radiation, atmospheric pressure and rainfall that affect the water circulation in North Aegean as well as the Coriolis force effect, are taken into account. The seasonal characteristics of the water circulation in the North Aegean are examined using a horizontal grid resolution of $4 \mathrm{Km}$ by $4 \mathrm{Km}$. The salinity, the water temperature and discharge from the Dardanelles straits are taken to be seasonally varied. The simulation was conducted for a total flow time of 6 years. According to the authors best knowledge the present paper constitutes the first numerical modeling attempt in the literature that apart from the long-term hydrodynamic characteristics that have also been studied in previous works, suitable tracers are introduced in order to predict the long term fate and distribution of pollutants that are transported from the Black sea into the North Aegean. The overall results of the present investigation indicate that a substantial percentage of pollutants originating from the Black Sea, accumulate in the North part of the Aegean Sea. The Black Sea Pollutant (BSP) concentration in the North Aegean surface waters reaches relatively high values $(20 \%-34 \%)$ of its initial assumed value $(100 \%)$ at the Dardanelles exit to the North Aegean, in a relatively short period of 6 years. Even at $500 \mathrm{~m}$ depth the BSP accumulation is more than $5 \%$ of its initial value.
\end{abstract}

Keywords: North Aegean Sea, Black Sea, Dardanelles, surface buoyant plume, Coriolis force, pollutant transport. 


\section{Introduction}

The North Aegean Sea lies to the Northeast of the Eastern Mediterranean and is bounded to the north and west by the Greek mainland, to the east by the coastline of Asia Minor and to the south by the South Aegean Sea. It is the region of the Mediterranean Sea where Black Sea waters enter through the Dardanelles Straits. The Black Sea-Dardanelles Straits-Aegean Sea system has a pronounced sea-level difference. The average sea level at the Black Sea is about $55 \mathrm{~cm}$ higher than at the Aegean Sea, but the slope along the system is non-linear, being much steeper in the Strait of Bosporus (Alpar and Yuce, 1997). The water exchange between the Black Sea and the eastern Mediterranean occurs through the Dardanelles Straits as a two-layer flow. The salinity and density fields of the water column in the Dardanelles Straits show a structure comprised of two homogeneous layers separated by an interfacial layer, with higher stratification in the eastern part of the Dardanelles, from the Marmara Sea to the Aegean Sea. The deeper water layer originates from the Mediterranean and has a salinity of 39 , while the surface layer originates from the Black Sea and has a salinity of 20 (Latif et al., 1992; Aksu et al., 1999). Strong mixing occurs at the west end of the Dardanelles Straits. As a result, about $40 \%$ of the Aegean influx is mixed with the upper layer by entrainment processes and returns back to the Aegean (Unluata et al., 1990). A main characteristic of the Black Sea Water (BSW) inflow in the North Aegean is its high velocity, around 0.5 to $0.85 \mathrm{~m} / \mathrm{sec}$, which is developed in the sea surface (Zodiatis and Balopoulos, 1993).

The North Aegean Trough constitutes one of the main bathymetric characteristics of the North Aegean Sea. It follows a northeast to southwest direction, beginning north of Limnos Island and ending to the Sporades islands complex. The North Aegean Trough itself is isolated below $350 \mathrm{~m}$ and has a water volume of $32 \times 10^{11} \mathrm{~m}^{3}$ below $500 \mathrm{~m}$. It is the deepest trench of the North Aegean Sea consisting of three deep basins: (a) the North Sporades basin with a maximum depth of $1500 \mathrm{~m}$, (b) the Athos basin with a maximum depth of $1100 \mathrm{~m}$ and c) the Limnos basin with a maximum depth of $1611 \mathrm{~m}$. The water volume of the Athos and Limnos basins, below $500 \mathrm{~m}$ depth, are $27.3 \times 10^{11}$ and $4.8 \times 10^{11} \mathrm{~m}^{3}$, respectively (Velaoras and Lascaratos, 2005; Lykousis et al., 2002).

The sea surface temperature of the North Aegean Sea is associated with the meteorological conditions which define the air temperature. The annual variation of the surface water temperature is between 13 to $25^{\circ} \mathrm{C}$, with the lower value to be appeared on 
February and the higher on August-September, when the salinity is increased (Poulos et al., 1997; Zervakis et al., 2004).

The sea surface salinity also varies spatially and seasonally, ranging from less than 33 , in the north, to more than 39 , in the southeast. Sea surface salinity values present their maximum differences during summer, whilst during winter and autumn their distribution is more uniform (Poulos et al., 1997, Kanarska and Maderich, 2008).

The water density at the sea surface, is primarily affected by the temperature and salinity distribution. The formation of the east - west pycnocline in the North Aegean Sea is due to the Etesian winds that are developed during the summer period in combination with the water inflow from the Black Sea. The formation of the north - south pycnocline is due to the entrapment of the Black Sea Water (BSW) in the sea surface layer above the Samothraki continental shelf and the north Aegean trench (Georgopoulos, 2002).

The wind field in the north Aegean is dominated by north-northeasterly winds during the warm period which are called, Etesian winds. This wind system (associated with clear skies) persists for extended periods and often reaches gate force in strength. The Etesian winds usually blow from 8 o'clock in the morning until 8 o'clock in the night. During winter, strong, cold and dry northerlies are funneled with high intensity through the river valleys of the North Aegean (e.g. Axios, Strimon and Evros), towards the North Aegean Sea (Poulos et al., 1997).

The water volume of the North Aegean Sea is estimated to be approximately $3.5 \times 10^{13}$ $\mathrm{m}^{3}$ which consists of three distinct water masses, these are:

a) the surface waters originating from the Black Sea, characterized by low salinity and water temperature,

b) the intermediate waters originating from the east Levantine basin, characterized by high salinity and water temperature and

c) the deep waters which occupy the deep basins of the north Aegean, characterized by very high water density.

The interaction of the above mentioned distinct water masses which present strong deviations to their physicochemical and biogeochemical parameters, results in a much stronger stratification in the water column of the North Aegean Sea than the corresponding stratification in the South Aegean Sea (Krasakopoulou et al., 2002; Zervakis et al., 2004). The water inflow from the Black Sea has a major influence in the formation of the North Aegean Sea stratification. The simultaneous occurrence of the maximum atmospheric cooling and the 
minimum inflow discharge of the BSW at the end of winter, contribute to the reduction of buoyancy in the surface layer, facilitating dense water formation processes in the region (Tzali et al., 2010).

The dynamics of the BSW plume and its interaction with the irregular coastline and topography (islands, bays, straits) plays an important role in the hydrodynamic structure of the North Aegean Sea. Initially, the Black sea waters are directed to the west and then deviate to the north. Thus, during their movement they subject to strong mixing with the deeper water layers (Zodiatis and Balopoulos, 1993; Sofianos et al., 2002).

The water residence time in the North Aegean Sea is strongly influenced by the Cyclades plateau, which geographically appears as a physical obstruction in the water exchange between the North and South Aegean Sea. In addition, the water circulation in combination with the very high stratification of the upper layers increases the residence time of the water of the upper layers in the wider region of the North Aegean. As a result, water that has out-flowed from the Black Sea in the winter, forms a separate distinct layer in the region during spring, and is still traceable in the water column in late summer (Zervakis and Georgopoulos, 2002).

Up to present, there are various numerical investigations dealing with the hydrodynamic circulation in the North Aegean Sea. A first approach towards an ocean forecasting system for the Aegean Sea is presented in the work of Korres et al. (2002). The ocean forecasting component is part of the POSEIDON system which includes high resolution atmospheric and wave modeling of the Aegean Sea together with an extended network of observational buoys, for the continuous monitoring of physical, biological and chemical parameters. The ocean forecast model system consists a high-resolution $\left(1 / 20^{\circ} \times 1 / 20^{\circ}\right.$ that corresponds to $4.1-4.8 \mathrm{~km}$ by $5.3-5.7 \mathrm{~km}$ horizontal computational grid) implementation of the Princeton Ocean Model (POM) forced by forecast surface fluxes of momentum, heat and freshwater provided by the regional ETA atmospheric model.

In the work of Kanarska and Maderich (2008) the POM model is applied to study seasonal hydrodynamics variability in the Dardanelles straits. Seasonal monthly values of the volume exchange at the Aegean and Marmara exits were estimated. It is found that the seasonal exchange dynamics is governed by the turbulent friction and entrainment at the Dardanelles area.

The seasonal characteristics of the circulation in the North Aegean Sea are examined with the aid of a climatological type simulation on a fine resolution grid $(2.5 \mathrm{~km}$ by $2.5 \mathrm{~km})$ in 
the work of Kourafalou and Barbopoulos (2003). The model is based on POM with a parameterization of plume dynamics that is employed for the input of waters with hydrographic properties that are different than the properties of basin waters, as the BSW outflow through the Dardanelles Straits and other riverine sources. The model is nested with a sequence of coarser regional and basin-wide models that provide for the long-term interaction between the study area and the Eastern Mediterranean at large. The results are employed to discuss the response of the North Aegean to the important circulation forcing mechanisms in the region, namely wind stress, heat and salt fluxes, buoyancy due to rivers and the BSW outflow.

The impact of the BSW inflow on the circulation and the water mass characteristics of the North Aegean Sea are investigated using POM, in the work of Tzali et al. (2010). A horizontal computational grid of $1 / 60^{\circ} \times 1 / 60^{\circ}$ is used to perform four climatological numerical experiments, exploring the effects of the exchange amplitude at the Dardanelles Straits in terms of the mean annual volume exchanged and the amplitude of its seasonal cycle.

Furthermore, in Androulidakis et al. (2009) a three-dimensional high-resolution (grid spacing $1 / 50^{\circ}$ ) hydrodynamic model based on the Hybrid Coordinate Ocean Model (HYCOM) has been implemented in the North Aegean to execute several numerical simulations in order to examine the important and complex circulation forcing mechanism in the region.

Finally, in Blain et al. (2009) the Advanced Circulation Model (ACIRM) and HYCOM are coupled in order to model the Black Sea plume that outflows from the Dardanelles Straits into the North Aegean Sea.

All these previous investigations highlight the influence of the Black Sea water plume in the hydrodynamic characteristics of the North Aegean Sea. However, according to the authors' best knowledge there are not any previous investigations dealing with the transport paths, dispersal patterns and concentration distributions of conservative pollutants that are passively transported from the proposed plume into the North Aegean. Moreover, it is true that the fate of the Black Sea pollutant inputs, is not well known, because the in situ data do not provide sufficient coverage for the long term behavior of Black Sea inputs in the entire domain of the North Aegean. This type of investigation is of vital importance, since the long term fate of the North Aegean Sea ecosystem may be seriously threatened in the future decades, by the continuous transport and accumulation of pollutants that originate from the already environmentally deteriorated Black Sea. Therefore, the aim of the present paper is to 
investigate numerically, the long term fate and accumulation of pollutants transported from the Dardanelles plume into the North Aegean, apart from the hydrodynamic behavior of the brackish, surface buoyant plume that is formed from the BSW discharge into the North Aegean Sea through the Dardanelles Straits, that has also been studied by previous researchers. The proposed numerical simulation is conducted with the use of the ELCOM (Estuary and Lake Computer Model), which was developed in the Center of Water Research in the Western Australia University and is a widely used and robust numerical model, for the hydrodynamic simulation of lakes, estuaries and enclosed seas. It should be mentioned that the proposed numerical model results, are validated through quantitative and qualitative comparison with available in the literature field data.

\section{Methods}

\subsection{Description of the hydrodynamic model ELCOM}

The ELCOM (Estuary, Lake and Coastal Ocean Model) that is used for the numerical simulation of the present paper, is a three-dimensional hydrodynamic model for estuaries, lakes and enclosed seas, and is mainly used to predict the variation of water temperature and salinity in space and time (Hodges, 2000). It applies hydrodynamic and thermodynamic models to simulate the temporal behavior of stratified water bodies with environmental forcing. The hydrodynamic simulation method solves the unsteady, viscous Navier-Stokes equations for incompressible flow using the hydrostatic assumption for pressure. Modeled and simulated processes include baroclinic and barotropic responses, rotational effects, tidal forcing, wind stresses, surface thermal forcing, inflows, outflows, and transport of salt, heat and passive scalars. The hydrodynamic algorithms are a semi-implicit, finite-difference approach based on a second-order Euler-Lagrange advection of momentum with an implicit solution of the free surface evolution. Passive and active scalars (i.e. tracers, salinity and temperature) are advected using the conservative ULTIMATE QUICKEST discretization. The transport equations are the unsteady Reynolds-averaged Navier-Stokes (RANS) as well as scalar transport equations, using the Boussinesq approximation and neglecting the nonhydrostatic pressure terms. The free surface evolution is governed by a vertical integration of the continuity equation applied to the Reynolds-averaged kinematic boundary condition. 
Heat exchange at the atmosphere-ocean interface is separated into penetrative (solar radiation) and non-penetrative components (long wave radiation and sensible and latent heat fluxes). Solar radiation penetrates into the water following an exponential decay as described by Beer's Law (Imberger and Patterson, 1990). Sensible and evaporative heat losses are variable across the water surface and are described by standard bulk transfer equations that are corrected to account for the effects of atmospheric stability (Imberger and Patterson, 1990). The user is required to supply meteorological information (e.g. solar radiation, windspeed and direction, humidity and air temperature) and inflow and outflow volume fluxes.

ELCOM is implemented in Fortran 90 so that three-dimensional space can be mapped into a single vector for fast operation using array-processing techniques. Only the computational cells that contain water are represented in the single vector so that memory usage can be minimized. This allows Fortran 90 compiler parallelization and vectorization without platform-specific modification of the code (Imberger and Patterson, 1990). Further details regarding the ELCOM model can be found at the ELCOM's Science Manual (Hodges and Dallimore, 2001).

\subsection{Model inputs and set up}

The selected region of the North Aegean Sea that is considered for the numerical simulation of the present investigation is depicted in Figure 1. As it can be seen, it is bounded to the north and west by the Greek mainland and to the east by the coastline of the Asia Minor. The south open sea boundary is located approximately at the south end of Chios Island. A rectangular computational grid was constructed, consisting of uniformly distributed horizontal cells with a breadth and width of $4 \mathrm{~km}$, (Figure 1). In the vertical direction 200 layers of $5 \mathrm{~m}$ thickness each, were used. Therefore, the first $1000 \mathrm{~m}$ depth are taken into account for the simulation. At this point it should be mentioned that the water volume contained at deeper levels (from $1000 \mathrm{~m}$ up to the maximum water depth of $1500 \mathrm{~m}$ ) is quite small (approximately 1.5\%) in comparison to the total water volume of the north Aegean see, due to the complex bathymetry, and trial simulations indicated that its inclusion do not affect the model predictions. Therefore, for computational speed-up purposes, it is not taken into consideration. Furthermore, as it can be seen by the present investigation results and as it is known from previous studies (Zervakis and Georgopoulos, 2002; Velaoras and Lascaratos, 2005) the maximum water depth that the studied buoyant surface plume can be detected in the entire North Aegean basin, is approximately 50m. Therefore the $1000 \mathrm{~m}$ depth taken into consideration in the present investigation, can be considered adequate. According to Hodges 
and Dallimore (2010), such a fine resolution, vertical, homogeneous grid performs better and with greater computational accuracy, in relation to a non-homogeneous grid (varying thickness of vertical cell layers). Therefore, in the present investigation, the choice of such a fine and uniform vertical grid resolution was made, in order to study the evolution of water column stratification, the vertical distribution of tracer's concentration in the lower water sea layers and to evaluate their long-term accumulation at the bottom layers, with uniform (over the entire computational domain) and adequate computational accuracy. Moreover, before the selection of the proposed grid, a sensitivity analysis using coarser as well as non-uniform computational grids, indicated small appreciable differences in the predicted quantities. However, using the fine and uniform grid, the computational efficiency and stability gain during the calculations was large (kopasakis, 2012). In the bottom layer a turbulent benthic boundary condition was applied, while the viscosity value was taken to be constant. For best computational accuracy the constructed grid was rotated clockwise from the north 17.48 degrees, so that the Dardanelles outflow was parallel to the horizontal grid lines. A summary of the model set up, the applied forcing as well as the initialization and validation data is given in Table 1.

The selected calculation time step was $3 \mathrm{~min}$ and a total real flow time of 6 years was simulated. For the simulation of one year of real flow, approximately 5 days of calculation execution was required in an Intel Core $\mathrm{I} 7$ processor at $3.06 \mathrm{GHz}$ with $8 \mathrm{~GB}$ of RAM.

The starting date for the simulation was the beginning of winter on 1 January 2005, when the water column was well-mixed and freshwater inputs were more energetic at the wider area in the vicinity of the Dardanelles exit to the North Aegean. The corresponding ending date was on 31 December 2010. Winter is defined as December-February, spring as March-May, summer as June-August and autumn as September-November. The BSW entering the model domain via the Dardanelles Straits and the water of the North Aegean Sea exiting the model domain at the Hellespont, were simulated as point sources. Weekly discharges, according to literature values, were used for inflows and outflows at Dardanelles (Figure 2). The river inflows in the North Aegean Sea were ignored, as they can be considered negligible in relation to the massive mean annual discharge from the Dardanelles Straits. The Dardanelles discharge is about 15 to 17 times greater than the total discharge of the North Aegean rivers (Georgopoulos 2002, Poulos et al., 1997). However, taking into consideration that an important part of the physical rivers outflow is retained within various dams upstream of the river mouths, for irrigation purposes, then the BSW outflow is even much greater than 
17 times (estimated 30 to 60 times). However, there are some important coastal BSW circulation patterns, that under specific conditions may be influenced in local scale by the river outflows (i.e. Evros river water outflow. However, the Evros river outflow influences the water circulation locally, in the vicinity of the coastal area of Alexandroupolis. In the work of Georgoulas (2010), numerical simulations indicate that the surface water plume that is formed by the Evros river discharge, during extreme flood conditions, is limited to the North Aegean coastal area, directed to the west of the river mouth due to the Coriolis force effect, since most of the discharged fresh water by the river, is entrapped and carried along to the sea bottom by subaqueous, particle-laden density currents (turbidity currents). This finding is in contrast with Kanellopoulos et.al., (2009) assumptions that the Samothraki's plateau circulation pattern is affected by the Evros river discharge.

The maximum and minimum discharges in the upper layer occur in winter and summer, respectively. Mean annual values of the discharges at the Aegean exit are at about $38820 \mathrm{~m}^{3} / \mathrm{s}$ in the upper layer and $30000 \mathrm{~m}^{3} / \mathrm{s}$ in the bottom layer. The seasonal variability of volume fluxes in the bottom layer of the Aegean exit is $9600 \mathrm{~m}^{3} / \mathrm{s}$. The variability of the discharges in the upper layer is much weaker (about $6115 \mathrm{~m}^{3} / \mathrm{s}$ ). These differences could be explained by the contribution of the baroclinic component that is caused by the density difference between the two basins (Kanarska and Maderich, 2008). The water inflow takes place within the first $10 \mathrm{~m}$ depth, while the water outflow takes place from $10 \mathrm{~m}$ to $55 \mathrm{~m}$ depth.

Two different tracers are used in order to monitor the pollutant inflow and dispersal from the Dardanelles, Tracer 1 and Tracer 2. These conservative, passive tracers are representing dimensionless concentration values with a range from 0 to 1 . Tracer 1 , which, from now on, will be called Black sea pollutant (BSP), represents the pollutant inflow from the Dardanelles, from the beginning of the simulation (year 2005), while Tracer 2 represents the inflow of a new pollutant (BSP2) from the Black sea in the North Aegean Sea, after 4 years of real flow (year 2009), that the simulation has already reached a dynamic equilibrium as it is explained in the following sections.

\subsection{Initial conditions, boundary conditions and forcing fields}

Initial conditions over the whole model domain were set in accordance to the varying temperature and homogeneous salinity time-series that were derived from literature sources (Kanarska and Maderich, 2008) and were used for the outlet at the Dardanelles exit (Figure 
2b). In more detail, according to Figure 2b, since the simulation begins on January of 2005 the initial condition for the water temperature and the water salinity over the entire computational domain is assumed to be $14.5^{\circ} \mathrm{C}$ and 38.9 , respectively. It should be mentioned that salinity units are according to the Practical Salinity Scale.

At the Dardanelles Straits exit boundary, the applied salinity and temperature of the inflowing and outflowing water are depicted, in Figures $2 \mathrm{a}$ and $2 \mathrm{~b}$, respectively. The twolayer exchange flow at Dardanelles is primarily controlled by mixing and friction at much shorter time scale. Therefore, the magnitude of Dardanelles outflow to the North Aegean alters weekly in response to local environmental conditions, such as the short term wind episodes. Therefore, in order to approach more realistically the impact of the Dardanelles outflow in the North Aegean, a high frequency (daily) superimposed forcing was applied for the outflow and inflow boundary conditions.

The open boundary condition for the model domain was selected at the boundary between the Northern and Southern basins (Figure 1), in order to minimize boundary-forcing effects on the main area of interest, in the Dardanelles outflow as well as in the circulation patterns of the North Aegean Sea. Model inputs for this boundary included homogeneous profiles of temperature and salinity derived from field measurements at stations in the Island of Mykonos by the Poseidon system of the Hellenic Centre of Marine Research. Typical salinity and temperature values that were used as open southern boundary forcing conditions are depicted indicatively for 3 years of simulation (2008-2010), in Figures 3a, 3b.

A 6 year period (2005-2010) of meteorological data consisting of 10 minutes frequency readings of solar radiation, air pressure, air temperature, relative humidity and rainfall height, measured at the Genisea meteorological station at North Greece, were applied over the entire model domain for the corresponding simulation period (2005-2010). Genisea station is stated in the city of Xanthi and belongs to the authority of the Democritus University of Thrace. Furthermore, wind data from stations at Genisea, Athos, Skyros Island and Lesvos Island, were interpolated onto the model grid to create a spatially variable wind field. The prevailing wind climate is characterized by wind speeds varying from $3 \mathrm{~m} / \mathrm{s}$ to $>7.5 \mathrm{~m} / \mathrm{s}$, with strong northerly winds prevailing in summer and even strongest (up to $16 \mathrm{~m} / \mathrm{s}$ wind speed) northeasterly winds in winter (Poulos et al., 1997). The resultant surface water velocity fields were compared to those derived using only Genisea wind data in the entire domain, in order to investigate the role of variable wind forcing in driving surface circulation in the N.Aegean. Since some local quantitative and qualitative differences where found the 
results presented in the present paper, use the spatially variable wind field that better represent real conditions. Typical values of these meteorological data from Genisea and Lesvos stations are illustrated in Figure 4, indicatively for the years 2009 and 2008 respectively.

\section{Results}

\subsection{Model validation}

Despite the fact that prior set up and validation of the proposed model, for the Northern Adriatic Sea, provides enough confidence for the accuracy and reliability of the results (Spillman et al., 2007), the numerically predicted hydrodynamic results of the present investigation are also validated through extensive, quantitative and qualitative comparison with measured data that are available from literature sources.

In order to quantitatively assess the model performance in reproducing field measurements, model fitness was measured by evaluating the $r^{2}$ (determination coefficient). The vertical distribution of water salinity and temperature was validated on local and regional scales. Modeled surface water circulation was validated with Sea Surface Circulation (SC) images, generated from the Poseidon system of the Hellenic Centre for Marine Research.

The development of summer stratification, winter overturn and intermediate transitional periods is evident both in measured (Poseidon Athos Station Northwest of Limnos Island) and simulated (present study) water temperature (Figures 5a, 5c, 5e and 5g) and salinity (Figure 5b, 5d, 5f and 5h) time series, at various water depths. Moreover, the corresponding coefficients of determination $\left(r^{2}\right)$ for temperature and salinity values over the year 2009 were $0.82-0.99$ and 0.67-0.94 respectively, indicating that the model is reproducing the observed values adequately (Figures 9a, 9b). As it can be seen from Figure 5, the simulated timing of the creation and breakdown of stratification (high temperature and salinity gradients) was May and January respectively, in agreement with the corresponding observations at the Athos station.

Figures 7 and 8, shows a comparison between measured (Evangeliou et al., 2009) and modeled (present investigation) average water temperature, salinity and density, for a range of depths, at 3 measuring positions (L.1, L.2, L.3) at the east of Limnos Island on December of 2005 and June 2006, respectively. The position of the sampling points is depicted in Figure 6. The modeled data of Figure 7 and Figure 8 concern the same simulation period that the 
seawater samples were collected during the proposed field measurement cruises. According to Figures 7a, 7b, 7c the average water temperature, at stations L.1, L.2 and L.3, varied between $14.2^{\circ} \mathrm{C}$ to $16.2^{\circ} \mathrm{C}$ in a range of depth between $4 \mathrm{~m}$ to $65 \mathrm{~m}$. The small variation of the water temperature with depth, shows once again that a full-mixed water column is achieved during winter. The relatively lower average surface temperature and salinity values at station L.1 in Figures $7 \mathrm{a}, 7 \mathrm{~d}$, indicate the BSW effect in the specific area. As it can be seen from Figure 7 the simulated temperature and salinity profiles at the stations L.1, L.2 and L.3 are close with that of the measured profiles. This is more evident in Figures 10a and 10b where the corresponding determination coefficients are calculated $\left(r^{2}=0.76-0.89\right.$ and $\left.r^{2}=0.91-0.95\right)$.

From Figure 8, it is evident that the numerically predicted profiles (present study) are very close to the corresponding field measurements (Evangeliou et al., 2009). This is more evident in Figure 10c were the corresponding determination coefficients between the compared data are calculated. As it can be seen, the model was able to explain $97 \%-99 \%$ of the observed density variability in the calibration month of June $2006\left(\mathrm{r}^{2}=0.97-0.99\right)$. In general, both the numerically derived as well as the field measured density profiles at the 3 sampling points, are characterized by steep density gradients at the first $20 \mathrm{~m}$ depth, indicating the presence of the Black Sea plume in the area and the corresponding high water column stratification that is developed during the summer period.

Modeled velocities of the generated surface currents (present investigation) were validated with online available data from the CORI Prevention and Management of Sea Originated Risks to the Coastal Zone surface currents measuring system of Poseidon (Hellenic Centre for Marine Research, 2010), on the east coast of Limnos Island, as illustrated in Figure 11. These data are high quality and accuracy surface current data published online for validation and other research purposes. Comparisons of the corresponding velocity fields, show that the model successfully captures the main flow schemes of the specific area that are derived from CORI, both in velocity magnitude and direction. In more detail, the inflow from the Dardanelles Straits, on February, splits in two main streams (Figures 11a, 11c) the first stream is directed to the south of Limnos Island, while the second stream passes through the islands of Limnos and Imvros. On May the Dardanelles surface water plume forms a mesoscale anticyclonic eddy around the Island of Imvros (Figures 11b and 11e) while on July this anticyclonic eddy appears with a much smaller diameter, spatially limited between the islands of Limnos and Imvros (Figures 11c and 11f). 
From the overall results presented in the present Subsection (Subsection 3.1), it can be concluded that the hydrodynamic numerical model that is used in the present paper, can adequately capture the major hydrodynamic characteristics of the North Aegean Sea in space and time.

\subsection{Hydrodynamic results}

The influence of the Dardanelles outflow on the North Aegean Sea, in conjunction with the seasonal transition and breakdown of salinity and thermal stratification, is illustrated in Figure 12, which compares computed salinity and temperature across a vertical transect from the Dardanelles Straits to Milopotamos on the Greek coast, in late spring (May), late summer (August), autumn (October) and early winter (December). According to Figure 12 in general, the presence of BSW surface plume in the surface of the North Aegean covers a layer around 40m deep in agreement with Zodiatis et al. (1996). During spring, water column temperatures are relatively uniform and the influence of the BSW surface plume is appeared mostly to the area situated around the Dardanelles entrance. As it can be seen, a quite strong thermal stratification occurs in August, with evidence of a well-defined thermocline, at a depth of approximately $25-30 \mathrm{~m}$, in the central part and $40-45 \mathrm{~m}$, in the east part of the vertical transect line (Figure 12c). However, the corresponding salinity stratification is spatially limited up to the first $200 \mathrm{~km}$ from the Dardanelles exit (Figure 12d). The breakdown of the summer stratification begins in middle October (Figures 12e and 12f), while in early December, the water column is comparatively relatively well mixed (figures $12 \mathrm{~g}$ and $12 \mathrm{~h}$ ) and the influence of the Dardanelles inflow on the North Aegean surface waters, is tracked mostly to the eastern margins and in depth up to $40 \mathrm{~m}$, due to the high brackish water discharge at the Dardanelles exit (Figure 12h). Western nearshore and offshore areas are weakly stratified from BSW inputs.

Simulated average monthly surface layer currents are shown in Figure 13 for August and December using spatially non-varying (from Genisea station only, Figure 13a) and varying (all four wind stations, Figure 13b) wind fields. In both cases, seasonal circulation patterns of the Dardanelles surface mega plume are evident, such as the open anticyclonic circulation of the plume at Imvros Island at the same time with the formation of the anticyclonic eddy at the Samothraki Island during spring and the strong cyclonic eddy in North Sporades basin together with the weaker cyclonic eddy in thermaikos gulf during summer. However, the spatially varying wind field produces a strong cyclonic eddy at the 
North Sporades basin in summer (Figure 13b), which is somewhat larger and more uniform than that generated by the homogeneous wind field (Figure 13a). Moreover, the currents along the northeastern coastal area in spring are considerably weaker (Figure 13d) compared with the corresponding results from homogeneous wind field (Figure 13c). Due to, these local differences the wind field that is adopted for the simulation of the present paper is the spatially varying field, as it more close to the real wind conditions. An atmospheric model for wind fields could also have been used instead, but this was beyond the scope of the present investigation.

The interaction of the Dardanelles discharge, the Coriolis force and the wind action in the North Aegean, produces various anticyclonic and cyclonic circulations. At this point it should be mentioned that trial simulations without the Coriolis force and the wind forces effects, indicated that the generated surface water currents, contained no gyres and the Dardanelles surface mega plume tended to spread more widely across the entire computational domain. This highlights that Coriolis forces, coupled with the prevailing northeast wind patterns, are the main factors that generate the predominantly anticyclonic circulation patterns in the N.Aegean Sea. The strong northeast winds acting in the North Aegean basin tends to enhance the anticyclonic circulation in the area, whilst the thermohaline forcing that is higher in summer due to the strong stratification of the water column, tends to enhance the cyclonic circulation (Tzali et al., 2010).

During summer the main surface water current of the Black Sea Water that outflows from the Dardanelles, is directed rapidly through the islands of Limnos and Imvros, and reaches the south part of Thasos Island. Then is directed east reaching the south part of Athos peninsula and enhances the strong cyclonic eddy in the North Sporades basin. The semipermanent North Sporades cyclonic eddy (Olson et al., 2006) interacts with the surface water of Thermaikos Gulf, enhancing the formation of a semi-enclosed gyre during summer (Figure 14a). According to Figures 13d, small scale anticyclones are formed at the Samothraki Island in spring, due to the Dardanelles water plume movement. Furthermore, there it is evident that part of the Dardanelles plume is deviated north east after it reaches the south part of Imvros Island and moves along the northeast coastal area. According to Androulidakis and Kourafalou (2011), the development of this buoyancy-driven Coastal Current is controlled by the topography of the surround area. Moreover, the sea region of Athos is influenced by the anticyclonic flow of the BSW as well as by a series of transient mesoscale eddies. These eddies are associated with the strong thermocline and halocline at $30-40 \mathrm{~m}$ depth, as shown in 
Figures $12 \mathrm{c}-12 \mathrm{f}$, generated in the area, mostly during the summer and autumn, by the entrance of the fresh and cold BSW in a saline and warm environment in agreement with Nittis and Perivoliotis, (2002). Finally, during winter, as the Dardanelles plume approaches the Athos station, a strong anticyclonic gyre is formed in the area, with high current velocities up to $0.6 \mathrm{~m} / \mathrm{sec}$ (Figure $14 \mathrm{~b})$.

\subsection{Black Sea Pollutant dynamics results}

As mentioned previously, in order to monitor the fate of passive pollutants that originate from the Black Sea and are transported and dispersed through the surface buoyant plume that is hydrodynamically investigated in the previous subsection, two different conservative passive computational tracers, BSP and BSP2, are released at different times during the calculations, at the Dardanelles exit to the North Aegean. In more detail, BSP is released from the beginning of the simulation in order to investigate the long-term concentration accumulation, while BSP2 is released after the fourth year of the simulation in order to investigate the actual root and dispersal pattern at a time that a dynamic equilibrium has already been reached by the system.

The time evolution of the average daily BSP concentration in the entire domain of the North Aegean Sea is illustrated in Figure 15. As it can be seen, the BSP concentration is taking constant average values in the domain of the North Aegean Sea after 2 years of simulation, which means that the inflow from Dardanelles is equal to the outflow at the open boundary, and therefore a dynamic equilibrium has been reached in the model. Once the model has established a dynamic equilibrium, it is then obvious that it switches to a mode that depends solely on the transient character of the environmental forcing. The first two years of the simulation period are more dominated by the transient adjustment response. The small concentration fluctuations with respect to time show the combination of the model spin-up (transient) response and the response to the time-dependent forcing. The periodical large-scale fluctuation of the BSP concentration is seasonally varied and increases during the spring and summer period, when a strong stratification is developed in the water column. In the winter period the water column is comparatively well mixed and therefore a reduction of the BSP concentration occurs. In general, the BSP concentration decreases as the water depth increases. From the above it is evident that after the year 2007 the increasing trend of the seasonally varied BSP concentration at each depth, stabilizes showing only the seasonal 
variations that are repeated in the following years (2007-2010), indicating that a steady state has been reached to the simulated flow system.

Investigations of the BSP concentration were also made at the surface areas-stations (Athos, Limnos (L.1, L.2 and L.3)) where the model was earlier validated and calibrated. The results concerning two different simulation periods (December of 2009 and June 2010) are summarized in Table 2 and Table 3 respectively.

The spatial evolution of the BSP2 concentration at the surface layer with respect to time is depicted in Figure 16. As it can be seen and it will discussed in more detail in the following section, the BSP2 surface concentration field seems to be directly related to the North Aegean circulation patterns that were identified and presented at the previous subsection (Subsection 3.2).

\section{Discussion}

In the present section of the current investigation, a more detailed discussion of the overall results presented so far is conducted. In more detail Subsection 4.1 analyses the hydrodynamic regarding the generated North Aegean surface currents, Subsection 4.2 deals with the simulated temperature and salinity variations in the considered domain, while Subsection 4.3 discusses the behavior of the pollutants concentration transported by the Black Sea plume, in space and time.

\subsection{Surface water velocity field}

For validation purposes, the flow pattern of the Black Sea plume estimated by the ELCOM model was compared to CORI surface currents measuring system of Poseidon in Figure 11. The comparison shows agreement between the CORI-derived current vectors and the simulated flow pattern, concerning both directions and magnitudes.

The main feature of the circulation in the North Aegean Sea is the BSW current, with surface velocities up to $0.7 \mathrm{~m} / \mathrm{sec}$. The salinity and current speed at the North Aegean appears to be influenced by the strong seasonal discharge from the Dardanelles and the seasonal variability of winds. The main anticyclonic flow of the Dardanelles plume in the North Aegean, during summer (Figure 14a), which mainly passes through the islands of Limnos and Imvros, involves a relatively wide set of velocity vectors with the same direction, all at a high magnitude of approximately $0.50 \mathrm{~m} / \mathrm{s}$. This anticyclonic flow pattern that reaches the 
southeast part of Thasos Island and then diverted southwest approaching the North Sporades basin sets up one of the highest energy systems in the North Aegean domain. It is characteristic that at various points of the proposed current, meandering patterns and other instabilities are presented which induce the detachment of low salinity rings, as suggested by Vlasenko et al., (1996) and described by Tzali et al., (2010). This anticyclonic circulation highly effects the seasonal stratification of the surrounding area, including the islands of Limnos, Imvros and Samothraki. In Figure 11c it is evident that the small scale anticyclone that is formed between the Islands of Limnos and Imvros is the main reason that part of the Black Sea plume, is concentrated near the Limnos Island and the Dardanelles plateau, in agreement with the work of Kourafalou and Barbopoulos (2003).

During winter the BSW plume flow towards the northwest of Limnos Island, and splits in two streams. One stream is directed to the Athos basin and forms a strong semiclosed anticyclonic gyre with current velocities up to $0.5 \mathrm{~m} / \mathrm{sec}$ and the other moves anticyclonically along the southwest shelf of Limnos Island with speeds varying from $0.3 \mathrm{~m} / \mathrm{sec}$ to $0.4 \mathrm{~m} / \mathrm{sec}$ (Figure 14b).

From the above, it is evident that the main difference between the resulting BSW surface plume root and dispersal patterns between the summer and winter period, is that during June the BSW plume is deviated to the north before reaching to the Limnos Island, while during December it reaches the southeast Limnos and is separated into two different streams. This may be explained due to the combined effects of different initial momentum (different inflow discharge values) and water stratification conditions between the proposed periods.

\subsection{Temperature and salinity variation in the North Aegean Sea}

The cool Black Sea waters entering the North Aegean are identified by their low salinity and, consequently, density. During summer the surface layer is warmer than the water masses that occupy deeper depths (Figure 12c). This temperature variation together with the strong salinity variation in the water column of the North Aegean, due to the Black Sea water plume that flows in the upper see layer of the North Aegean, is the main reason of the strong stratification that is developed during the summer period. The initiation of the stratification breakdown that is observed during autumn (Figure 12e), is caused by the surface temperature cooling in relation to the high surface water temperatures during summer. Finally during 
winter the further reduction of the surface water temperatures, causes the almost complete weakening of the thermal stratification.

The salinity at the Athos station (Figures 5e, 5f) shows high values during winter that strongly decrease during summer and are generally influenced by the seasonal variations of the salinity at the Dardanelles Straits. A strong halocline front is generated in the area in middle summer, by the entrance of the brackish buoyant BSP waters, in a more saline environment (Figures 16a).

\subsection{Seasonal behavior of the pollutants concentration originating from the Black Sea plume}

The distribution of the BSP concentration at the North Aegean water column is illustrated in Figure 15. The BSP concentration appears to be high in the North Aegean domain, around $20-34 \%$, within the first $10 \mathrm{~m}$ depth from the sea surface, in a relatively short period of 6 years. It also increases with respect to time and is stabilized approximately after 2 years of real flow. As the water depth increases the BSP concentration decreases. In more detail at $15-20 \mathrm{~m}$ depth the BSP is about $20-30 \%$, at $25-30 \mathrm{~m}$ the BSP is $18-27 \%$ and at $35-50 \mathrm{~m}$ is $12-21 \%$ of its initial value that is assumed to be $100 \%$, at the Dardanelles exit. For depths from $100 \mathrm{~m}$ up to $250 \mathrm{~m}$ the BSP concentration is relatively low, with values varying from $10 \%$ to $16 \%$ approximately. Finally at the lower layers situated at depths greater than $400 \mathrm{~m}$ even lower but considerable values are encountered (up to 5\%). Taking into consideration that the water renewal is not succeeded for depths more than $400 \mathrm{~m}$ according to Kopasakis (2012), the BSP that is diffused and accumulated at the lower water see layers, remaining there for a long time.

According to Table 2, the concentration activity of the BSP, in 4 stations of the North Aegean (L.1, L.2, L.3 and Athos) on December 2009, ranged from 0.25 to 0.53 and from 0.11 to 0.13 at $5 \mathrm{~m}$ and $60 \mathrm{~m}$ depth, respectively. The maximum activity concentrations of the BSP that is traced at stations L1, L.2 and L.3, indirectly confirms that on December the main volume of the BSP is directed towards the south shelf of Limnos Island and splits in two streams. The first stream moves along the east part of Limnos Island and then is directed meandric to the south shelf of the Samothraki Island. The second stream moves anticyclonic along the west shelf of Limnos Island (Figure 16). As stations L1, L.2 and L.3 are located in the main route of the prevailing currents, they are considered to be more affected during winter. The ratio between the upper and lower layers activity concentrations of the 4 stations, 
varies from 1.9 to 4.8 . According to Table 3, during the summer period the maximum BSP concentration was observed in the station L.1 (44\%), which may be attributed to the semipermanent anticyclonic water mass movement that usually occurs from spring until early autumn (Figures 11c).

During February, March and April the BSP2 flow after its entrance in the N.Aegean splits in two streams (Figure 16). The first stream which is wider and stronger, under the Coriolis force effect, is diverted north moving along the southwest shelf of the Imvros Island and forming an anticyclonic eddy, while the second stream is directed to the south coastal area of Limnos Island. On May another flow of the BSP2 moves rapidly along the coastal shelf area that is situated above the Dardanelles entrance and is entering in the Gulf of Xiros. This flow is extended on June as far as the Gulf of Kavala in a narrow zone parallel to the mainland coastline, with relatively high concentration values (varying from $55 \%$ to $75 \%$ approximately). However, high BSP2 concentration values (up to $70 \%$ of its initial value at the Dardanelles entrance) also appear around the islands of Limnos and Imvros. On July the BSP2 flow is directed to the south part of Thasos Island where it bifurcates reaching the northern part of the Athos basin. Relatively high concentration values of the BSP2 $(60 \%$ to $65 \%$ of its initial value) are also shown in Figure 16, around the islands of Limnos and Imvros on August and September due to the presence of the strong anticyclonic gyre that is formed around the Limnos Island. On October the BSP2 flow enhances the strong semi-permanent cyclonic gyre that is formed to the North Sporades basin while part of this flow is entering the surface area of the Thermaikos Gulf. The BSP2 flow becomes less energetic on November and December when the breakdown of the water column stratification is achieved.

\section{Conclusions}

The present study constitutes an attempt to investigate interactions of the Black Sea inflow, the climate forcing, the water column structure and the BSP concentration over a range of time and space scales in the North Aegean Sea. The main objective is to quantify these effects using a dynamic modeling and mass balance approach. According to the authors' best knowledge, it is the first literature approach of modeling the Black Sea surface plume in the North Aegean using a seasonal Dardanelles discharge that differs from previous studies and it is based in the work of Kanarska et al. (2008) approach, of the water exchange in the Dardanelles straits. Moreover, it is the first time that apart from the hydrodynamic 
characteristics of the proposed phenomenon (velocity field, salinity and temperature distributions), the long as well as the short term fate and accumulation of pollutants that are transported from the Black Sea into the North Aegean Sea, is numerically predicted. The main conclusions and findings of the present numerical investigation are summarized below:

1) Physical processes such as brackish buoyant Black sea water inputs, vertical mixing and basin scale circulation, are delicately balanced.

2) The use of a 3D physical-hydrodynamic model such as ELCOM, is necessary to capture the large scale physical processes and to estimate the mass fluxes in this system with a high degree of spatial and temporal variability.

3) The numerically predicted results regarding the surface water currents as well as the temperature, salinity and density structure, are in adequate agreement with previously published field measurements.

4) The main factor that influences the North Aegean water circulation is the surface buoyant plume that is formed from the brackish waters discharging from the Dardanelles Straits, under the effect of the Coriolis force and the wind stresses.

5) The seasonality of BSW inflow rate is one of the major controlling factors for the regional stratification. The surface cooling and increased buoyancy inputs via Dardanelles discharge promote vertical mixing in early winter, causing the weakening of the water column stratification.

6) The use of passive Tracers shows that ELCOM can capture the BSP movement in the North Aegean Sea and can evaluate its dispersion and accumulation even in the lower water sea layers.

7) The BSP concentration at the surface water layers of the North Aegean reaches $34 \%$ of its initial release value (Dardanelles exit) during summer, while during winter it reduces to a corresponding value of $20 \%$. However, at greater depths $(>400 \mathrm{~m})$ the BSP concentration is still considerable showing an increasing trend with respect to time, reaching approximately $5 \%$ of its initial value.

Summarizing, the present paper verifies and evaluates the usefulness of a 3D numerical approach as a possible and quite suitable tool for future investigation on the hydrodynamic circulation of the North Aegean Sea as well as the long-term fate and accumulation of pollutants that originate from the Black Sea and are transported into the North Aegean Sea, through the Dardanelles Straights, allowing a wide range of parameters to be determined and continuously monitored with relatively high accuracy. Moreover, the 
overall results of the present paper add a significant contribution to the understanding of the complex flow processes that occur in the proposed region and justify the initial motivation and assumption by the authors that the long term fate of the North Aegean Sea ecosystem may be seriously threatened in the future decades, by the continuous transport and accumulation of pollutants that originate from the already environmentally deteriorated Black Sea.

Further investigation can be made with the parallel use of an environmental model such as CAEDYM, in order to achieve a biochemical approach of the North Aegean pollution due to the Dardanelles outflow with the inclusion of passive and active tracers such as dissolved oxygen, heavy metals, nutrients, and many others.

\section{References}

Aksu, A.E., Hiscott, R.N., Yasar, D., 1999. Oscillating Quaternary water levels of the Marmara Sea and vigorous outflow into the Aegean Sea from the Marmara Sea-Black Sea drainage corridor. Marine Geology 153, 275302.

Alpar, B., Yuce, H., 1997. Sea-level Variations and their Interactions Between the Black Sea and the Aegean Sea. Estuary Coastal and Shelf Science 46, 609-619.

Androulidakis Y., Kourafalou V., (2011), Evolution of a buoyant outflow in the presence of complex topography: The Dardanelles plume (North Aegean Sea), Journal of Geophysical Research, Vol. 116

Androulidakis, Y., Krestenitis, Y., Kourafalou, V. and Raitsos, D., 2009. Investigating the Black Sea waters contribution into the North Aegean Sea Hydrodynamic circulation. Proceedings of $11^{\text {th }}$ Conference of HHA and $7^{\text {th }}$ Conference of GCWRM, Volos Greece, Vol. II, pp. 929-936.

Besiktepe, S.T., 2003. Density currents in the two-layer flow: an example of Dardanelles outflow. OceanologicaActa26, 243-253.

Blain, C.A., Cambazoglu, M.K., Kourafalou, V.H., 2009. Modeling the Dardanelles Strait outflow plume using a coupled model system. Conference Proceeding of Marine Technology for Our Future: Global and Local Challenges, Biloxi, MS.

Evangeliou, N., Florou, H., Bokoros, P., Scoullos, M., 2009. Temporal and spatial distribution of ${ }^{137}$ Cs in Eastern Mediterranean Sea. Horizontal and vertical dispersion in two regions. Journal of Environmental Radioactivity 100, 626-636.

Georgopoulos, D., 2002. Water masses, dynamical structure and circulation in the North Aegean Sea (Greek edition). Ph.D. Thesis, University of Patra, Greece.

Georgoulas, A., 2010. Study of the density currents at rivers outflows due to suspended sediment particles. (Greek edition). Ph.D. Thesis, Democritus University of Thrace, Greece.

Hellenic Centre for Marine Research, Monitoring, Forecasting and Information System for the Greek Seas, 2010 , Data Base of Water Temperature and Salinity, HF Remote Sensing - the CORI system, Available from: http://poseidon.hcmr.gr/index.php.

Hodges, B., 2000. Numerical Techniques in CWR-ELCOM, CWR manuscript WP 1422BH, University of Western Australia.

Hodges, B., Dallimore, C., 2001. ELCOM Science Manual, CWR, University of Western Australia.

Imberger, J. and J.Patterson., 1990. Physical limnology. Advances in Applied Mechanics 27, 303-475.

Kanarska, Y., Maderich, V., 2008. Modelling of seasonal exchange flows through the Dardanelles Strait. Estuarine, Coastal and Shelf Science 79, 449-458.

Kopasakis K. (2012). 'Simulation of the hydrodynamic transport and diffusion of pollutants from the Black Sea into the North Aegean Sea with the use of hydrodynamic models and study of the effect of their long term accumulation to the environment of the N.Aegean Coastal area' (Greek edition). Ph.D. Thesis, Democritus University of Thrace, Greece.

Korres, G., Lascaratos, A., Hatziapostolou, E. and Katsafados, P., 2002. Towards an ocean forecasting system for the Aegean Sea. The Global Atmosphere and Ocean System. 8(2-3), 191-218.

Kourafalou, V.H., Barbopoulos, K., 2003. High resolution simulations on the North Aegean Sea seasonal circulation. Annales Geophysicae 21, 251-265. 
Krasakopoulou, E., Zervakis, V., Souvermezoglou, E. and Georgopoulos, D., 2002. North-eastern Aegean Sea: an effort to estimate steady-state N\&P budgets during September 1998. Mediterranean Marine Science 3/1, 43-53.

Latif, M.L., Ozsoy, E., Salihoglu, I., Gaines, A.F., Basturk, O, Y1lmaz, A., Tugrul, S., 1992. Monitoring via direct measurements of the modes of mixing and transport of wastewater discharges into the Bosphorus underflow. Middle East Technical University, Institute of Marine Sciences, Tech. Rep. 92-2, pp.98.

Lykousis, V., Chronis, G., Tselepides, A., Price, N.B., Theocharis, A., Siokou-Frangou, I., Van Wambeke, F., Danovaro, R., Stavrakakis, S., Duineveld, G., Georgopoulos, D., Ignatiades, L., Souvermezoglou, A. and Voutsinou-Taliadouri, F., 2002. Major outputs of the recent multidisciplinary biochemical researches undertaken in the Aegean Sea. Journal of Marine Systems 33-34, 313-334.

MEDAR Group, 2002. MEDATLAS 2002 Mediterranean and Black Sea Database of Temperature and Salinity and Climatological Atlas [CD-ROM], Eur. Comm. Mar. Sci. and Technol. Programme (MAST), Ifremer, Brest, France. Available from: www.ifremer.fr/sismer/program $/$ medar/.

Nittis, K., Perivoliotis, L., 2002. Circulation and hydrological characteristics of the North Aegean Sea: a contribution from real-time buoy measurements, Mediterranean Marine Science 3/1, 21-31.

Olson, D.B., Kourafalou, V.H., Johns, W.E., Samuels, G. and Veneziani, M., 2006. Aegean Surface Circulation from a Satellite - Tracked Drifter Array. Journal of Physical Oceanography 37, 1898-1917.

Poulos, S.E., Drakopoulos, P.G., Collins M.B., 1997. Seasonal variability in sea surface oceanographic conditions in the Aegean Sea (Eastern Mediterranean): an overview. Journal of Marine Systems 13, 225-244.

Sofianos, S., Johns, W., Lascaratos, A., Murray, S., Olson, D. and Theocharis, A., 2002. Draft report of the Aegean Sea Workshop. Aegean Sea Workshop, Rhodes, Greece.

Spillman, C.M., Imberger, J., Hamilton, D.P., Hipsey, M.R., Romero, J.R., 2007. Modelling the effects of Po River discharge, internal nutrient cycling and hydrodynamics on biogeochemistry of the Northern Adriatic Sea. Journal of Marine Systems 68, 167-200.

Tzali, M., Sofianos, S., Mantziafou, A., Skliris, N., 2010. Modelling the impact of Black Sea water inflow on the North Aegean Sea hydrodynamics. Ocean Dynamics 60, 585-596.

Unluata, U., Oguz, T., Latif, M.A. and Ozsou, E., 1990. On the physical oceanography of the Turkish Straits. In: L.J. Pratt (Eds), The Physical Oceanography of Sea Straits, Kluwer Academic Publishers, pp. 25-60.

Velaoras, D., Lascaratos, A., 2005. Deep water mass characteristics and interannual variability in the North and Central Aegean Sea. Journal of Marine Systems 53, 59-85.

Vlasenko VI, Stashchuk NM, Ivanov VA, Nikolaenko EG, Uslu O,Benli H (1996) Influence of the water exchange through the Dardanelles on the thermohaline structure of the Aegean Sea.Bulletin de I'Institut oceanographique 17, CIESM Science Series no. 2.

Zervakis, V., Georgopoulos, D., 2002. Hydrology and circulation in the North Aegean (eastern Mediterranean) throughout 1997 and 1998. Mediterranean Marine Science 3/1, 05-19.

Zervakis, V., Georgopoulos, D., Karageorgis, A.P. and Theoharis, A., 2004. On the response of the Aegean Sea to the climatic variability: a review. International Journal of Climatology 24, 1845-1858.

Zodiatis, G., Alexandri, S., Pavlakis, P., Johnsson, L., Kallos, G., Demetropoulos, A., Georgiou, G., Theodorou, A., Balopoulos, E., 1996. Tentative study of flow patterns in the North Aegean Sea using NOAA-AVHRR images and 2D model simulation. Annales Geophysicae 14, 1221-1231.

Zodiatis, G., Balopoulos, E., 1993. Structure and characteristics of fronts in the North Aegean Sea. Bollettino di Oceanologia Theorica ed Applicata XI (2), 113-124.

\section{Figure Captions}

Figure 1 North Aegean Sea bathymetry and horizontal computational grid that were used for the simulation of the present paper.

Figure 2 Typical seasonal variability of the discharge, salinity and water temperature at the North Aegean exit of the Dardanelles Straits, (a) in the upper (inflow) and (b) bottom (outflow) layer respectively (Kanarska and Maderich, 2008; MEDAR Group, 2002).

Figure 3 Open southern boundary forcing conditions for ELCOM, from Mykonos station for (a)Salinity, (b)Water temperature. 
Figure 4 Typical time series of (a) meteorological data recorded at the Genisea station in 2009 and (b) wind data at the Lesvos station in 2008 by Poseidon forecasting system.

Figure 5 (a),(b),(c),(d) Comparison of modeled (ELCOM) and measured (Poseidon) average water temperature, and $(\mathrm{e}),(\mathrm{f}),(\mathrm{g}),(\mathrm{h})$ comparison of modeled (ELCOM) and measured (Poseidon) average water salinity at Athos Station in 2009 for a range of water depths.

Figure 6 Sampling stations and main current circulation according to the work of Evangeliou et al., (2009).

Figure 7 (a),(b),(c) Comparison of modeled (ELCOM) and measured (Evangeliou et al., 2009) water temperature, and (d),(e),(f) comparison of modeled (ELCOM) and measured (Evangeliou et al., 2009) water salinity at Stations L.1, L.2 and L.3 on December 2005 for a range of water depths.

Figure 8 Comparison of modeled (ELCOM) and measured (Evangeliou et al., 2009) density profiles at Stations L.1, L.2 and L.3 on June 2006.

Figure 9 Comparison of Athos station modeled data and measured data for (a) temperature and (b) salinity and their respective $r^{2}$ values for the year 2009.

Figure 10 Comparison of stations L.1, L.2 and L.3 modeled data and measured data for (a) temperature and (b) salinity and their respective $r^{2}$ values for December 2009. (c) Comparison of density modeled and observed data and their respective $r^{2}$ values for June 2010 .

Figure 11 (a), (b), (c) Modeled velocities of the surface currents in the area close to the Dardanelles Straits and (d), (e), (f) SC images from CORI surface currents measuring system, for 8 February 2010, 13 May 2010 and 11 July 2010 respectively (Hellenic Centre for Marine Research, 2010).

Figure 12 Modeled seasonal salinity and temperature across a modeled vertical transect from the Dardanelles Straits to Milopotamos on the Greek coastline in (a),(b) late spring (May), (c),(d) late summer (August), (e),(f) autumn (October) and (g),(h) early winter (December) of year 2009.

Figure 13 Modelled surface circulation, generated using a homogeneous wind field for (a) 13/07/2010 and (b) 09/04/2010, and a fully interpolated wind field for (c) 13/07/2010 and (d) 09/04/2010.

Figure 14 Modeled surface water circulation for two seasons, (a) summer and (b) winter of 2010 in the North Aegean Sea.

Figure 15 Average daily values of the Black Sea pollutant concentration in the North Aegean, for various depths.

Figure 16 Movement of the BSP2, at the beginning of each month, for the year 2009.

\section{Table Captions}

Table $1 \quad$ Northern Aegean model: computational grid and model set-up, initial and boundary conditions and validation data sources.

Table 2 Vertical activity concentrations of modeled BSP for various stations in the North Aegean Sea (December 2009)

Table 3 Vertical activity concentrations of modeled BSP for various stations in the North Aegean Sea (June 2010) 


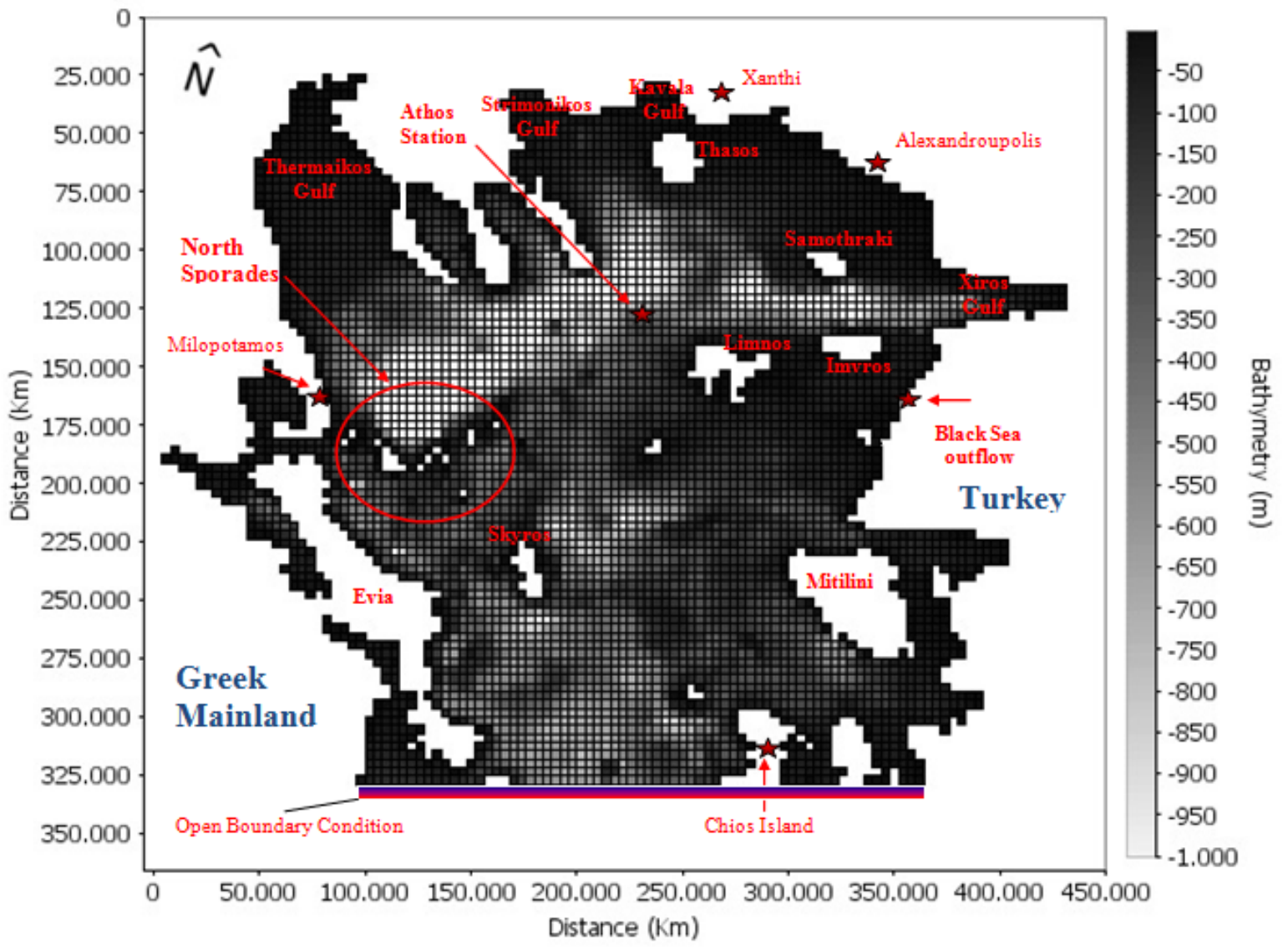

\section{Figure 1}
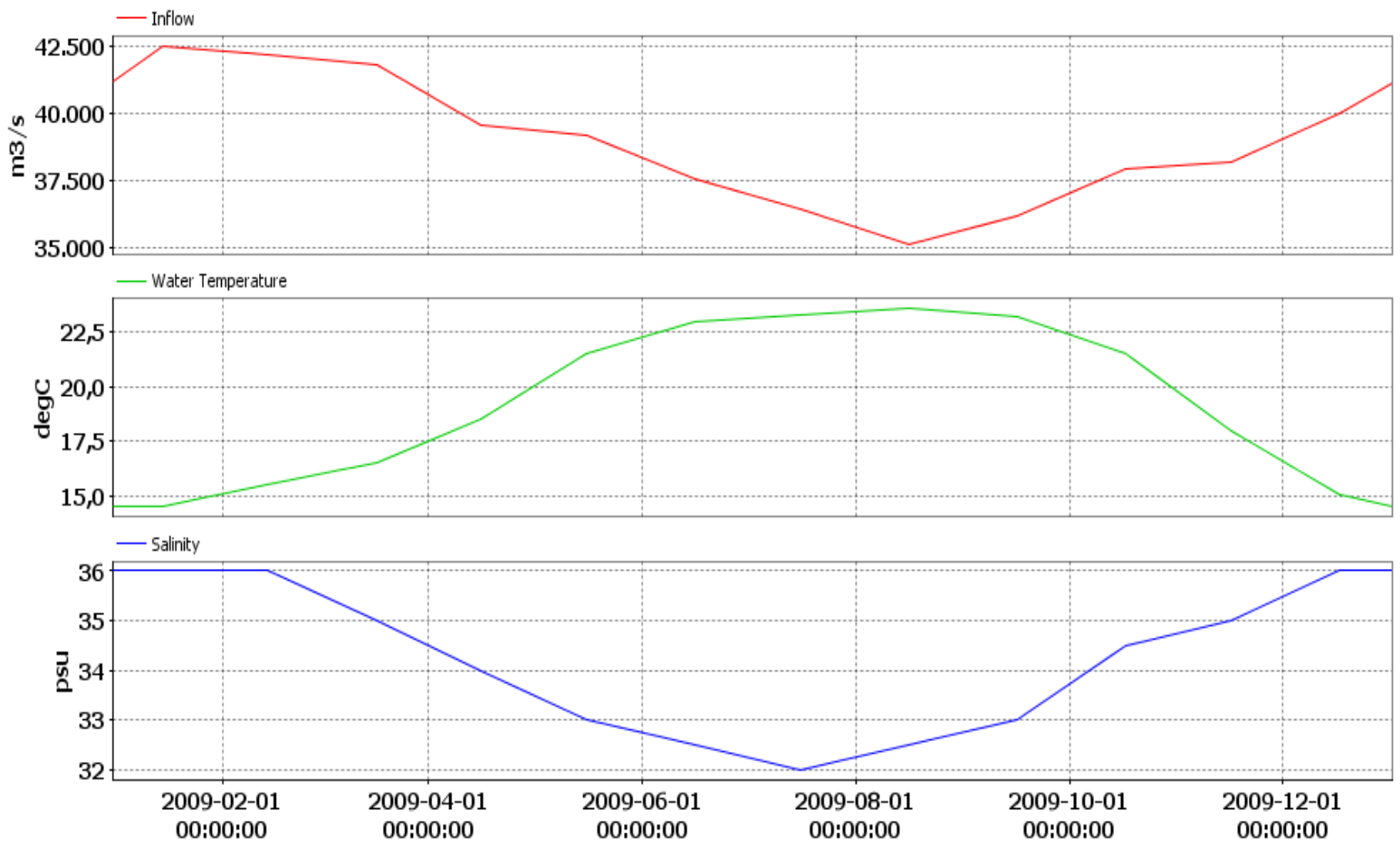
Figure 2(a)
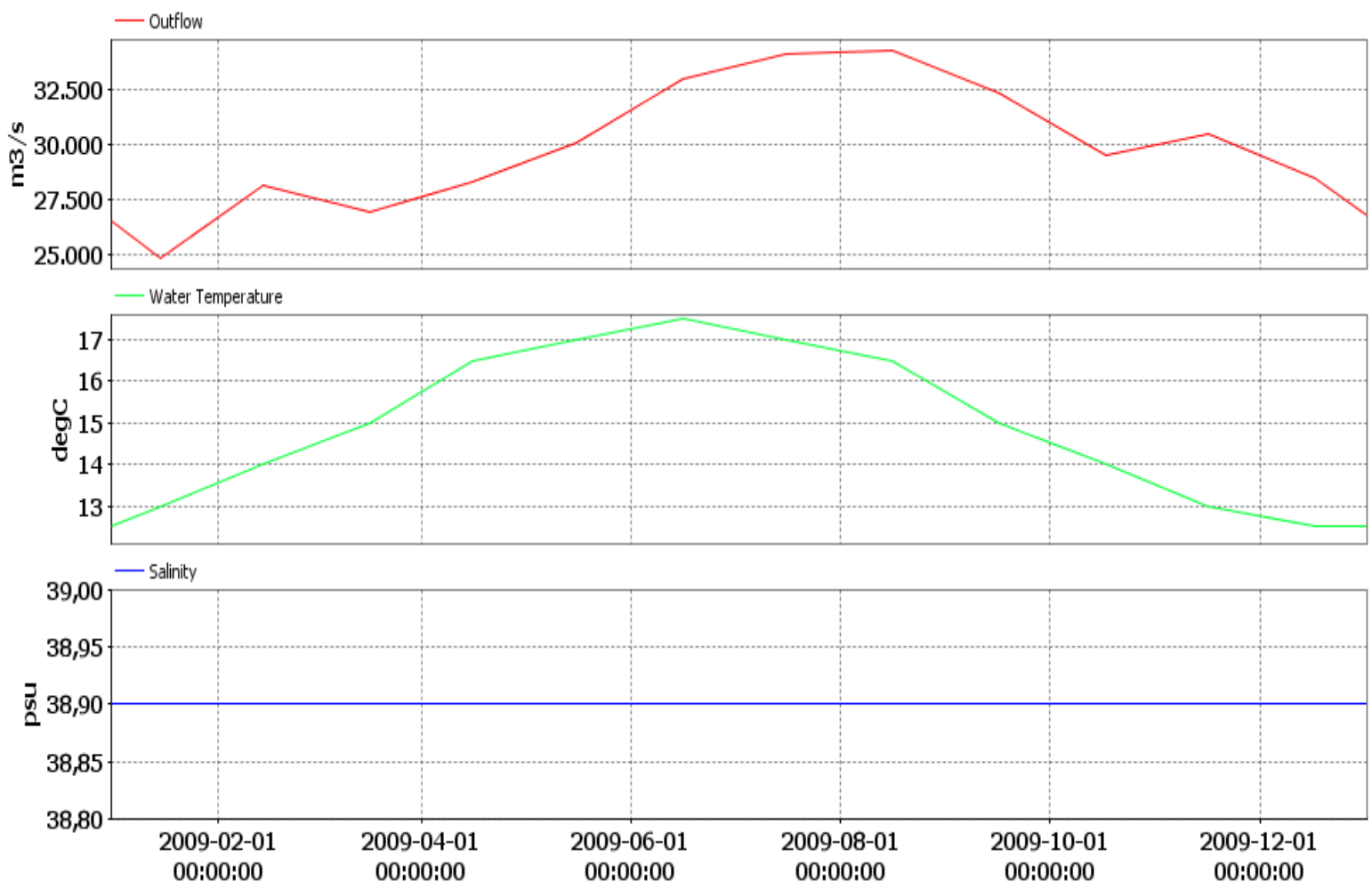

Figure 2(b)

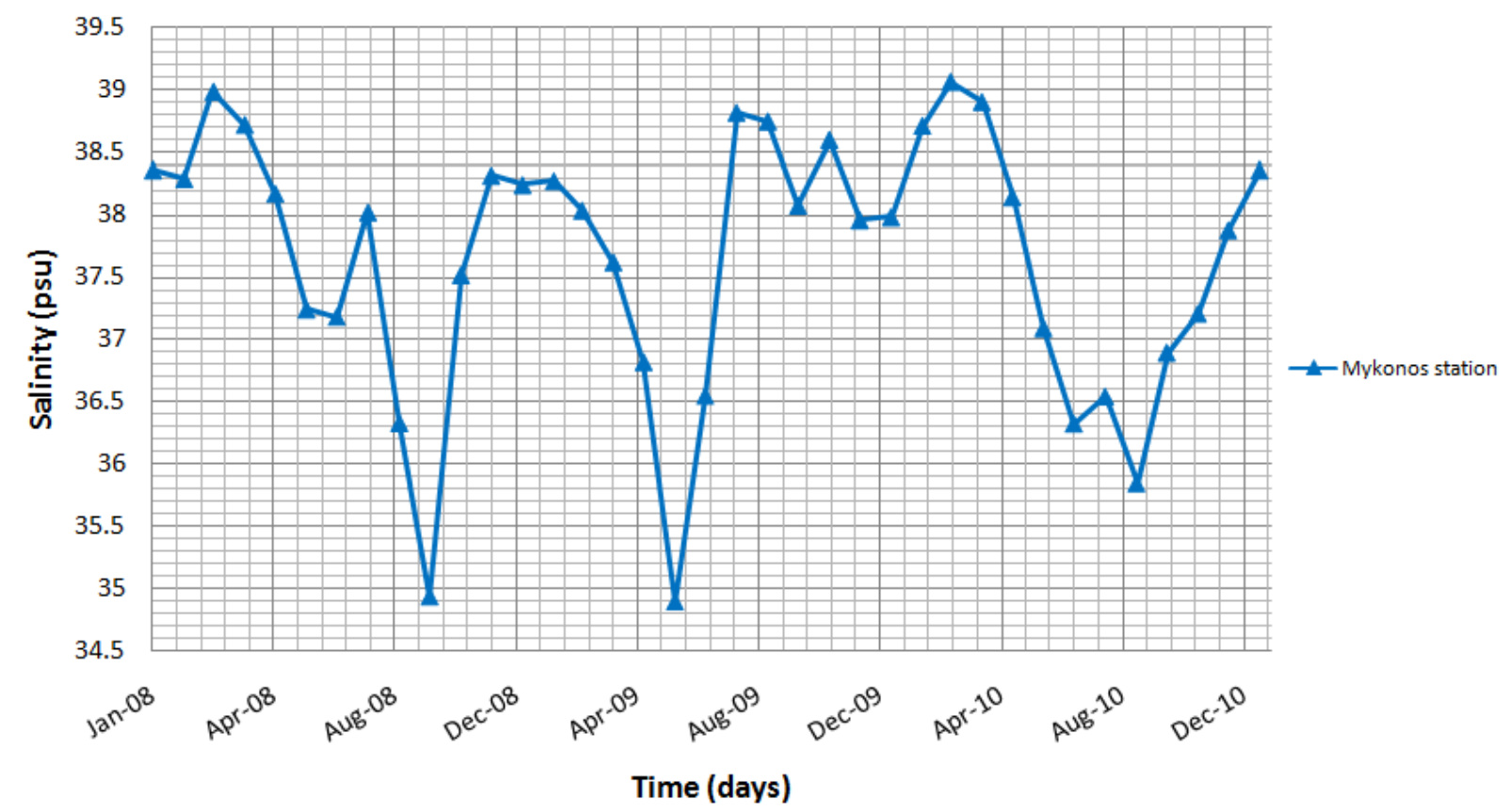

Figure 3(a) 


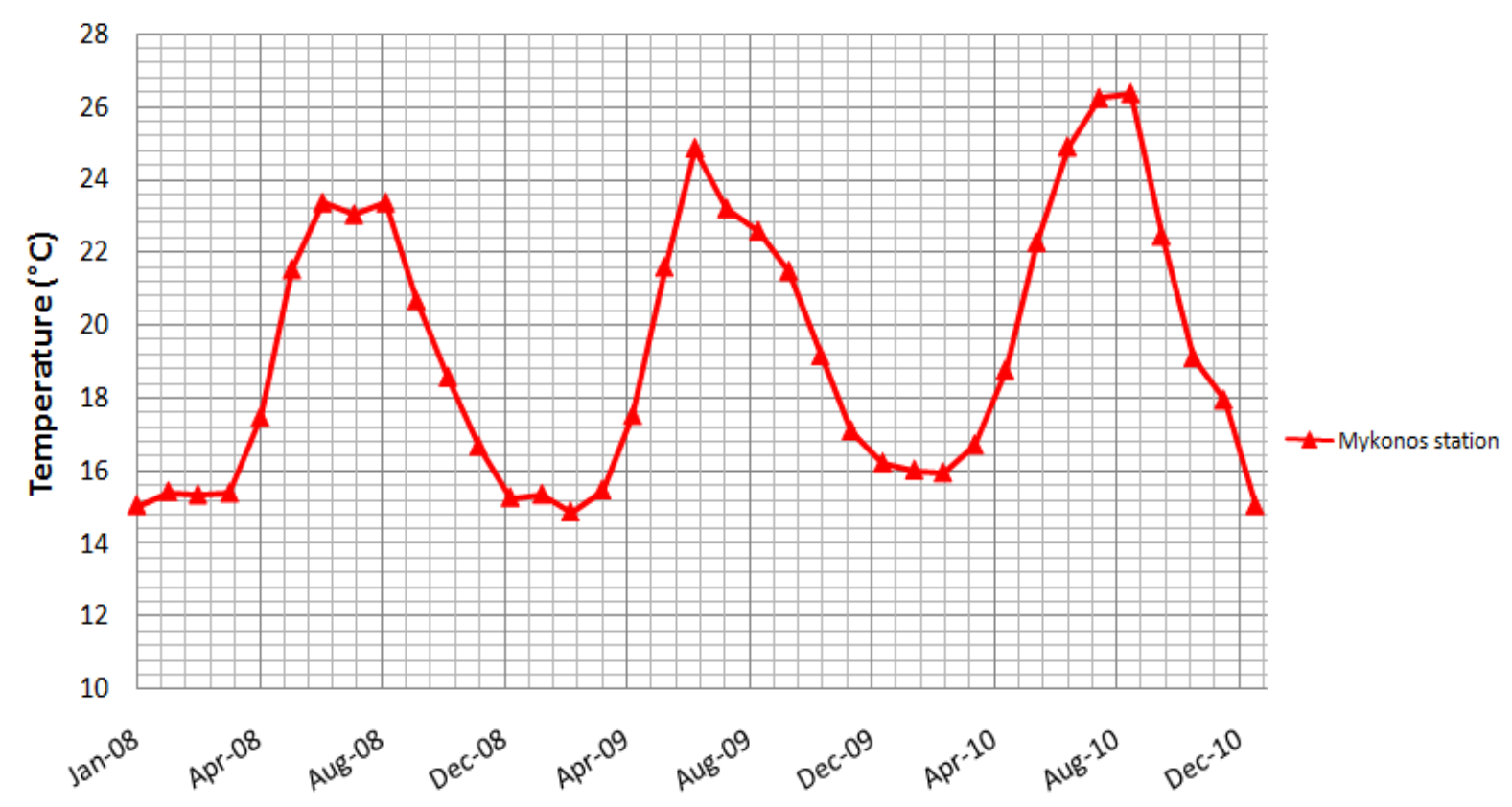

Figure 3(b)

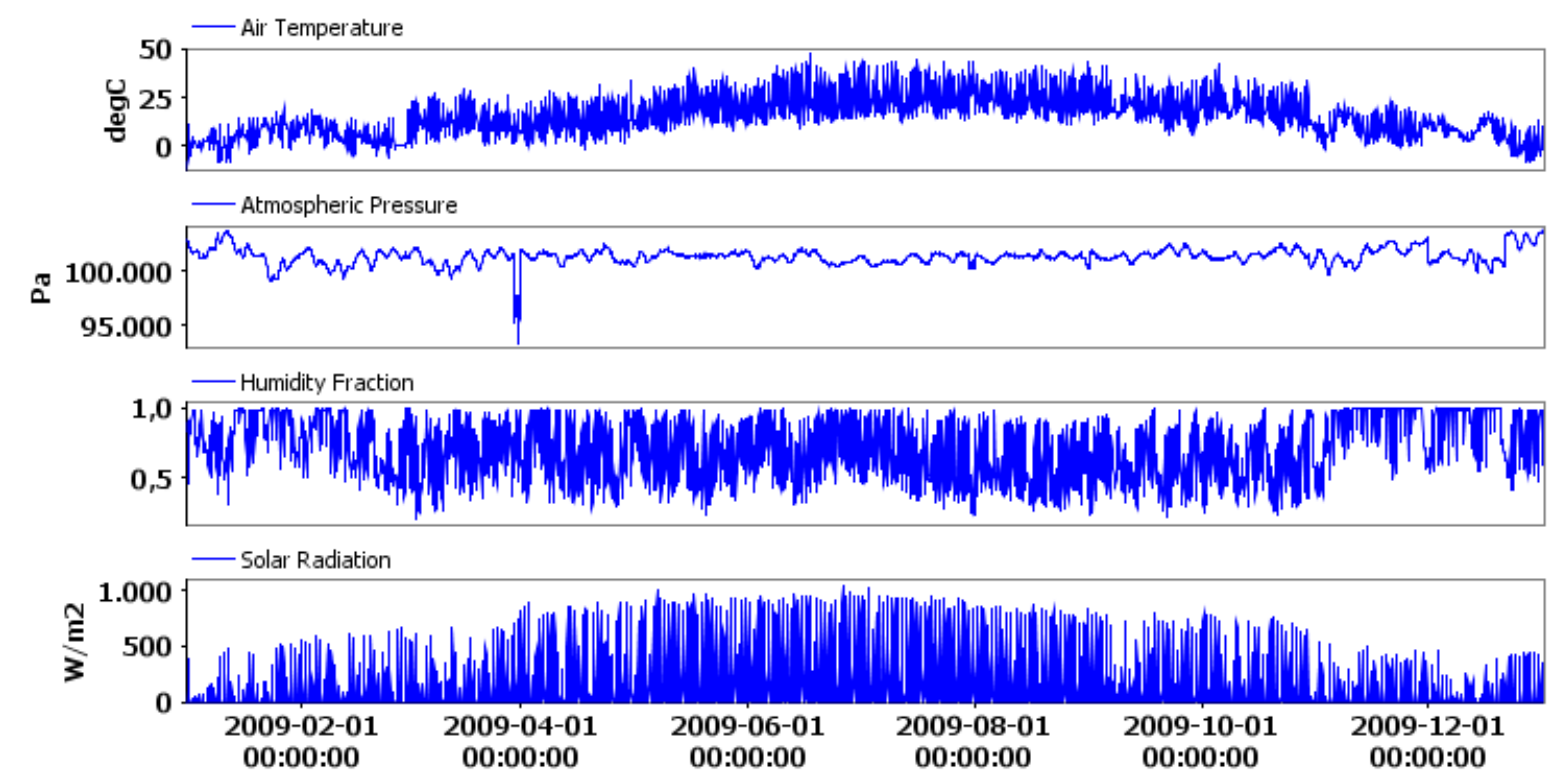

Figure 4(a)
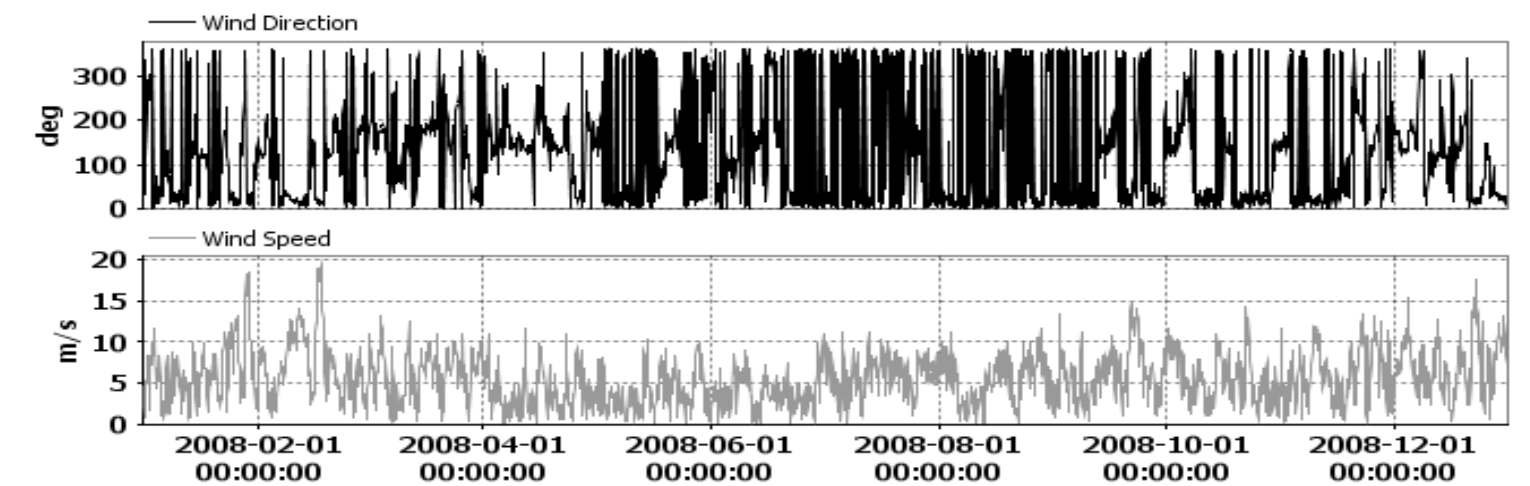

Figure 4(b) 


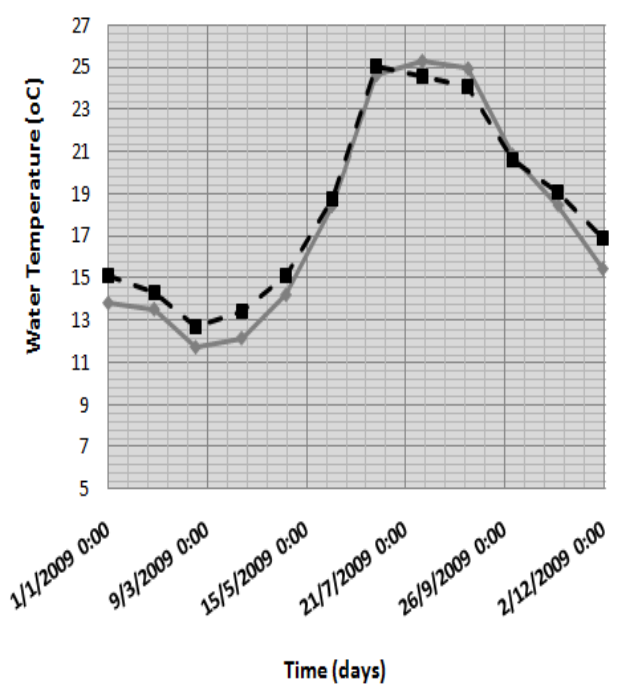

Figure 5(a)

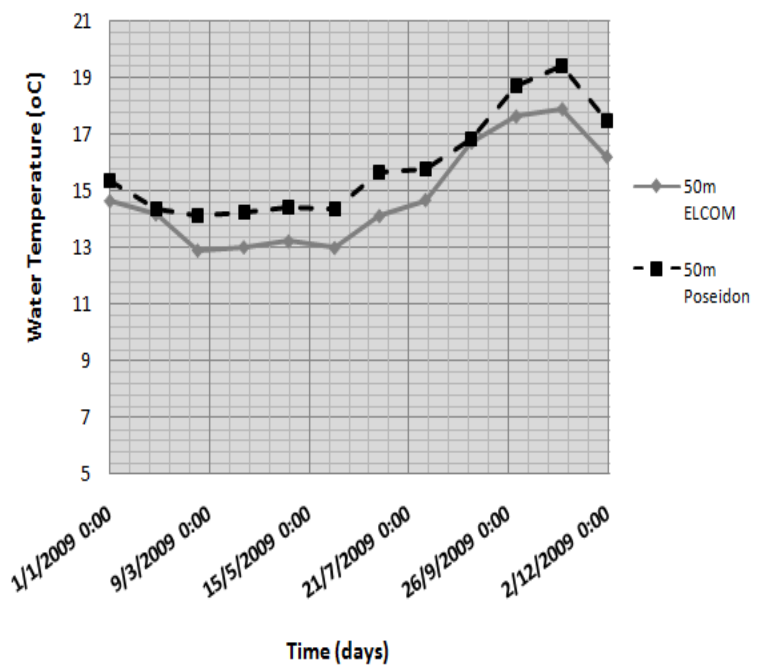

Figure 5(c)

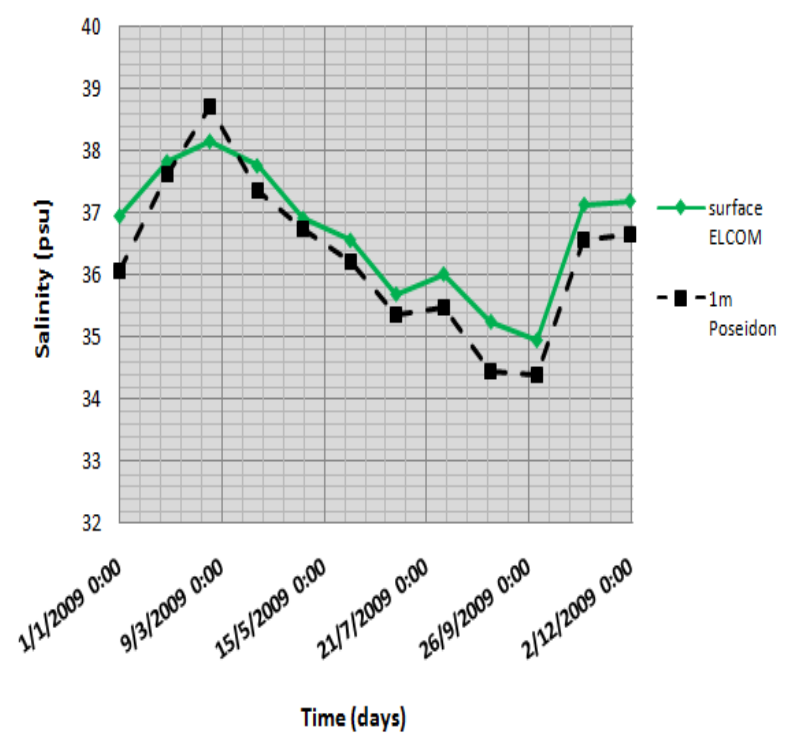

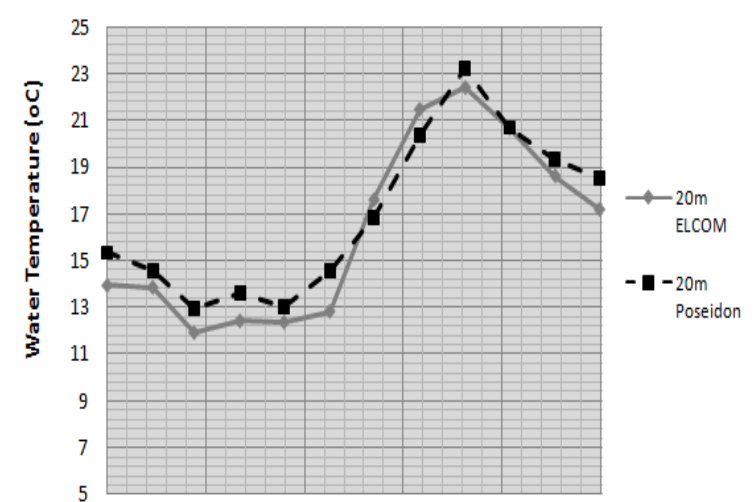

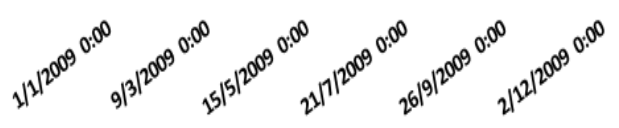

Time (days)

Figure 5(b)

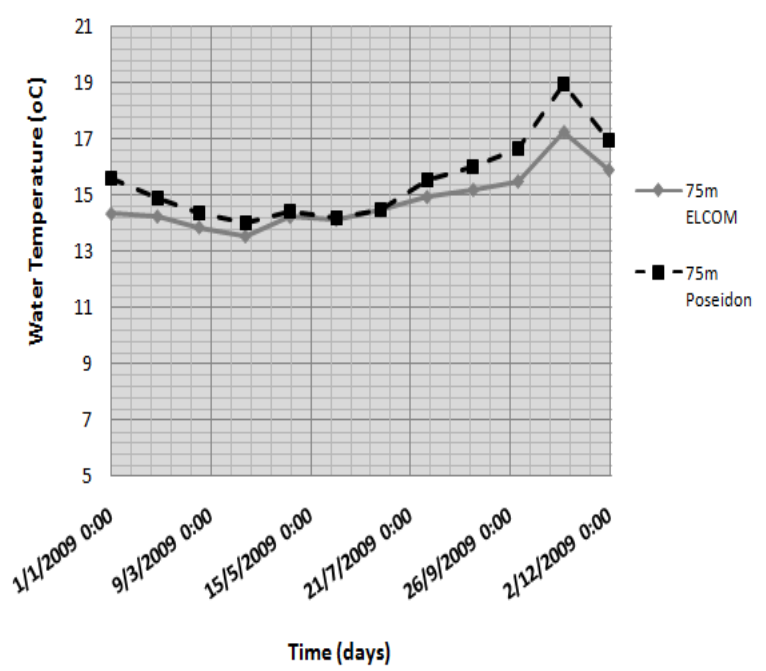

Figure 5(d)
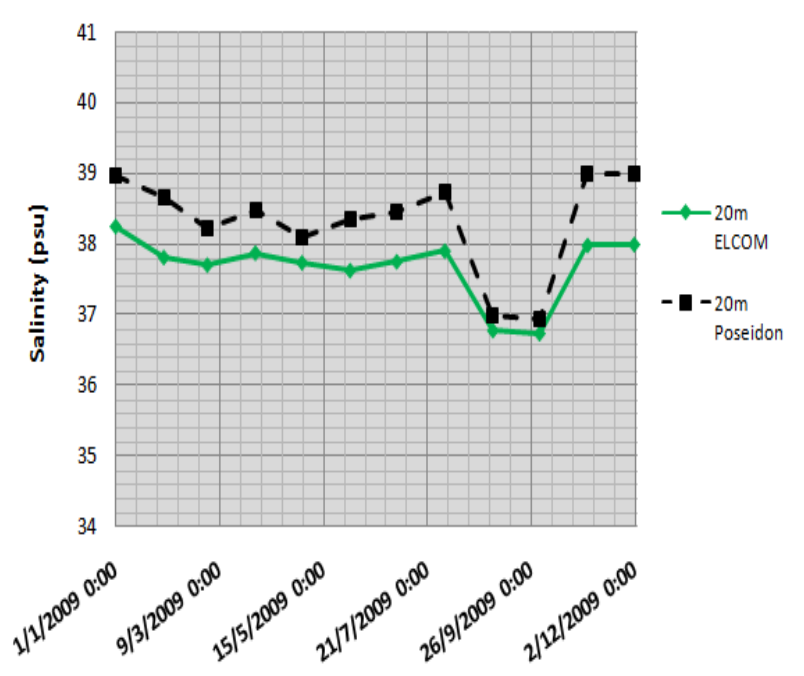

Time (days)

Figure 5(e)

Figure 5(f) 

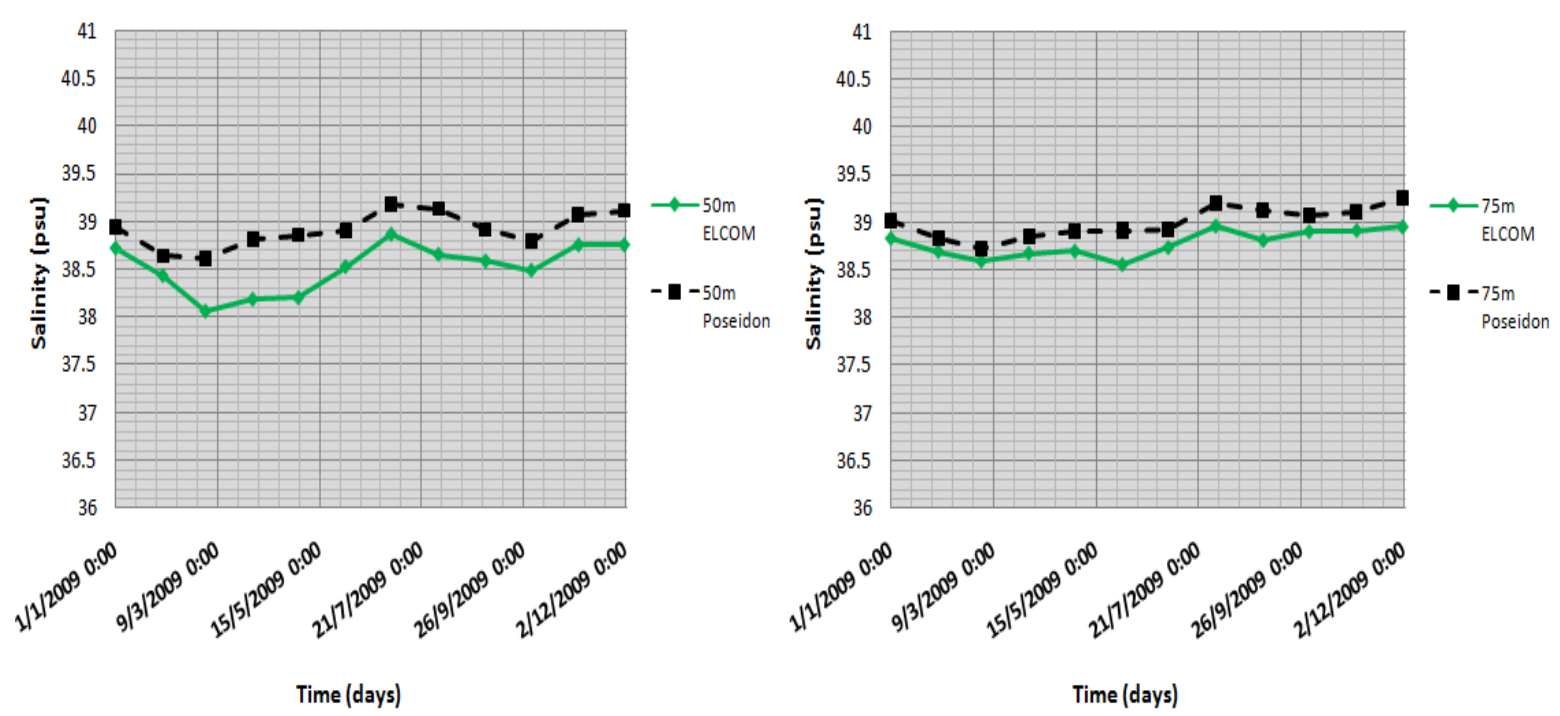

Figure 5(g)

Figure 5(h)

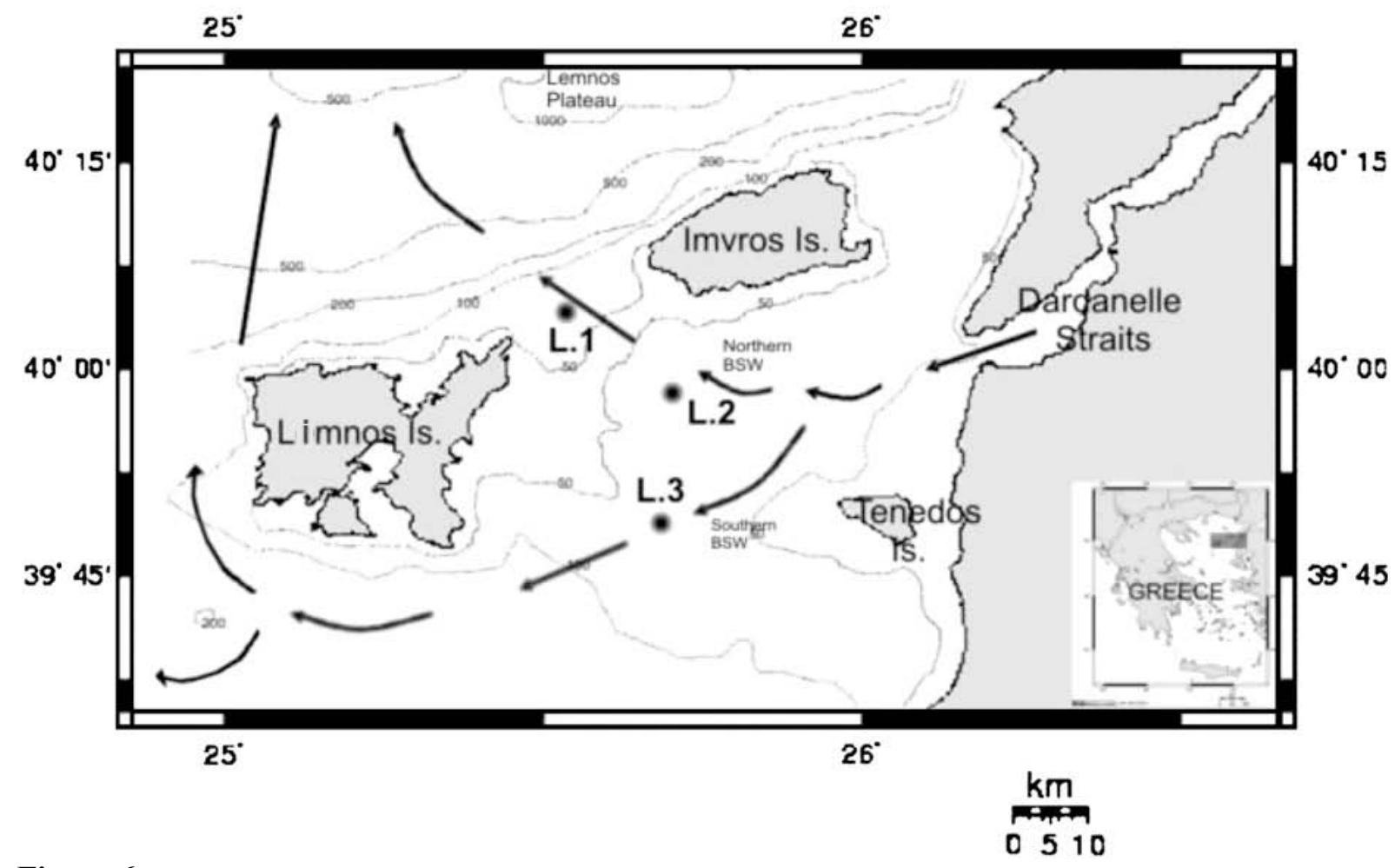

Figure 6 
Water Temperature $\left({ }^{\circ} \mathrm{C}\right)$

$\begin{array}{lllllllllll}10 & 11 & 12 & 13 & 14 & 15 & 16 & 17 & 18 & 19 & 20\end{array}$

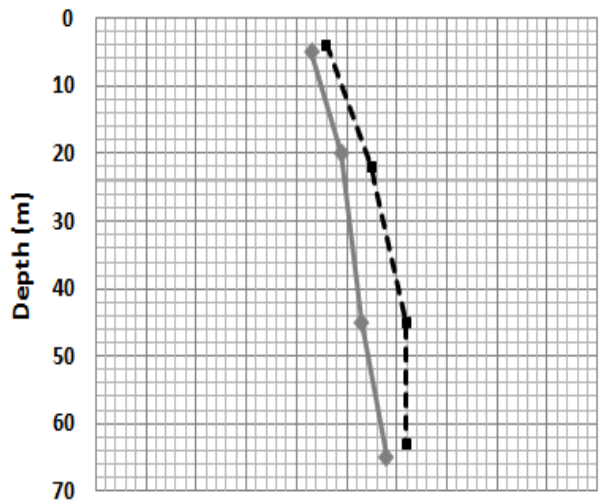

Figure 7(a)

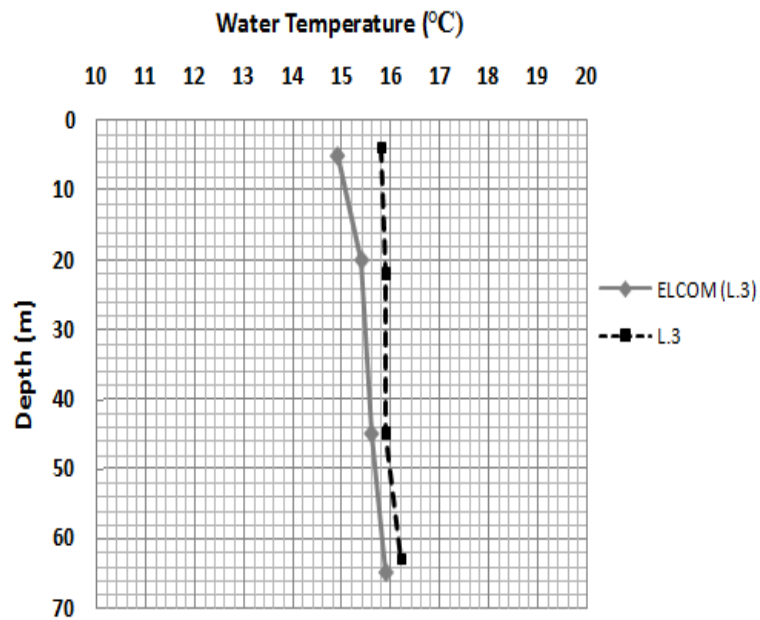

Figure 7(c)

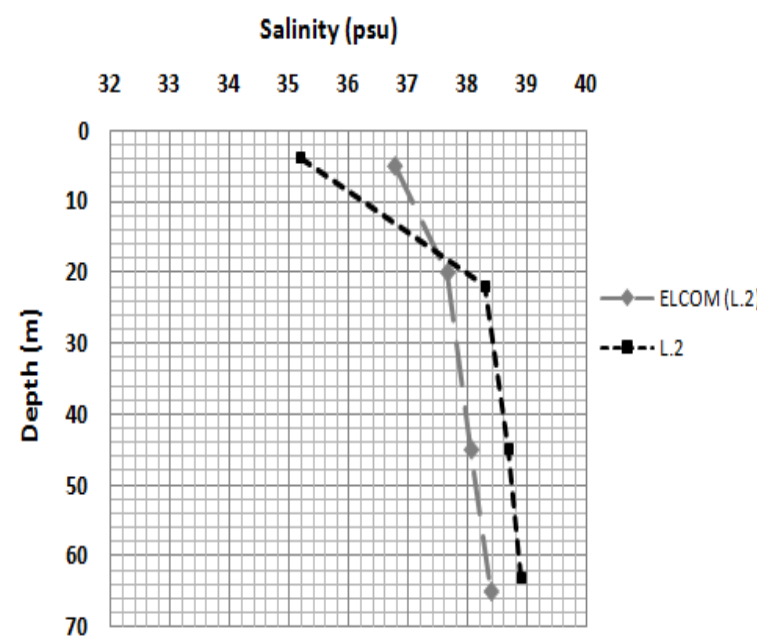

Figure 7(e)
Water Temperature $\left({ }^{\circ} \mathrm{C}\right)$

$\begin{array}{lllllllllll}10 & 11 & 12 & 13 & 14 & 15 & 16 & 17 & 18 & 19 & 20\end{array}$

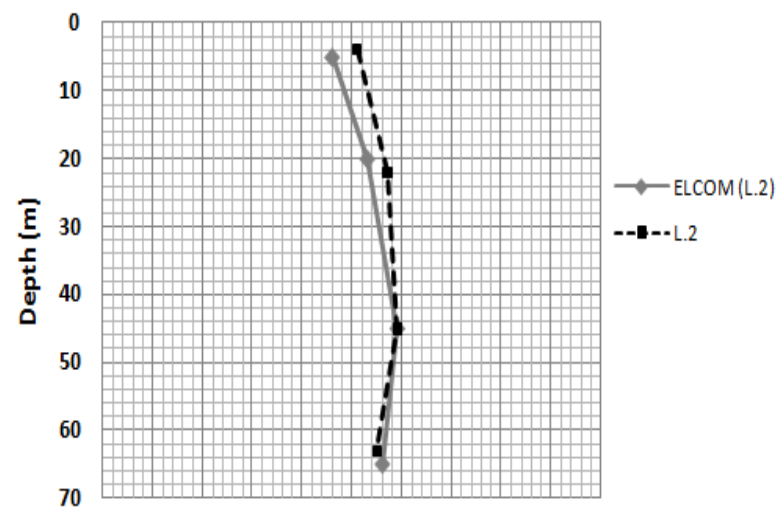

Figure 7(b)

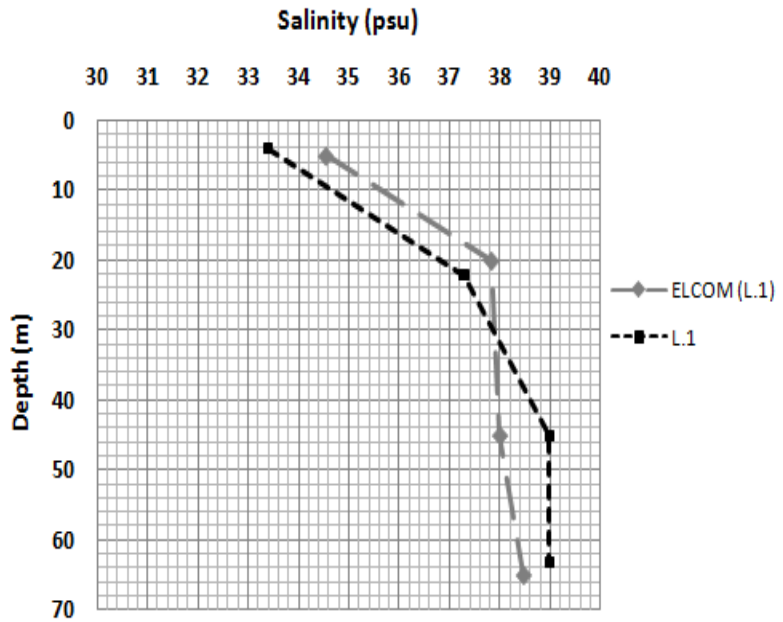

Figure 7(d)

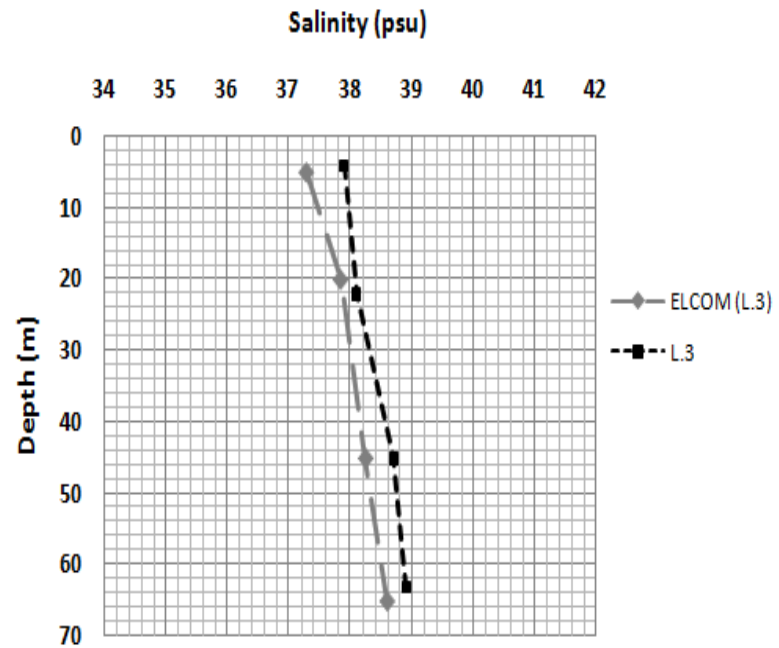

Figure 7(f) 
Density

$\begin{array}{lllllllllllll}20 & 21 & 22 & 23 & 24 & 25 & 26 & 27 & 28 & 29 & 30 & 31 & 32\end{array}$

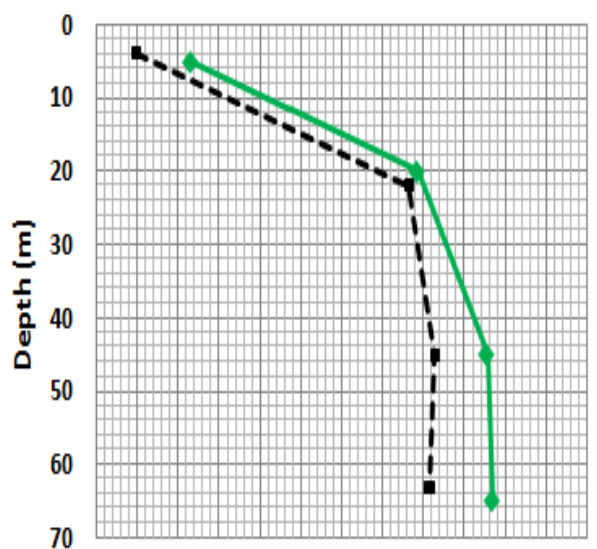

Figure 8(a)
Density

$\begin{array}{lllllllllllll}20 & 21 & 22 & 23 & 24 & 25 & 26 & 27 & 28 & 29 & 30 & 31 & 32\end{array}$

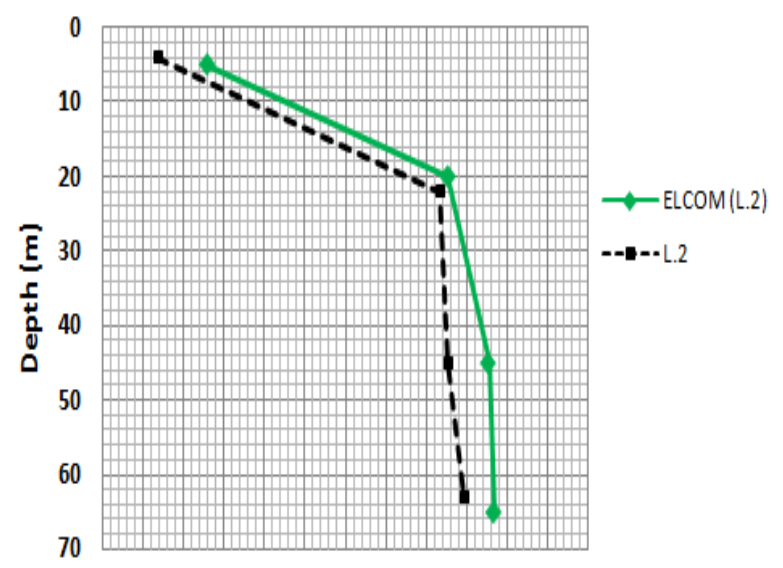

Figure 8(b)

Density

$\begin{array}{lllllllllllll}20 & 21 & 22 & 23 & 24 & 25 & 26 & 27 & 28 & 29 & 30 & 31 & 32\end{array}$

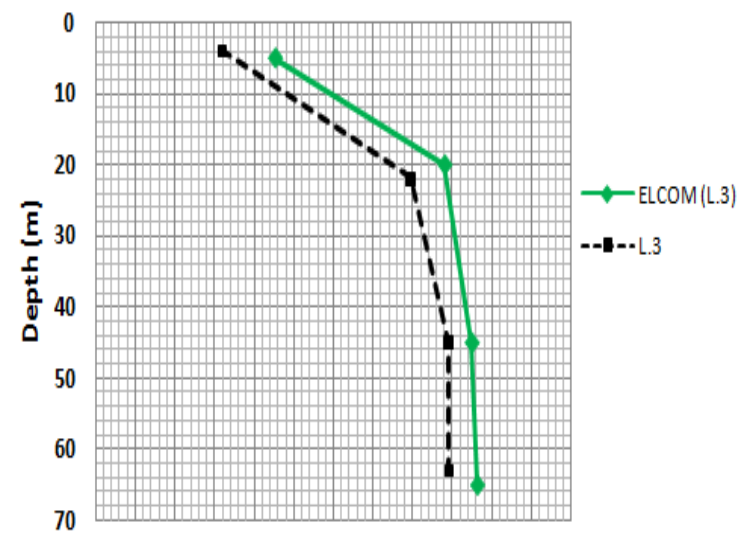

Figure 8(c)

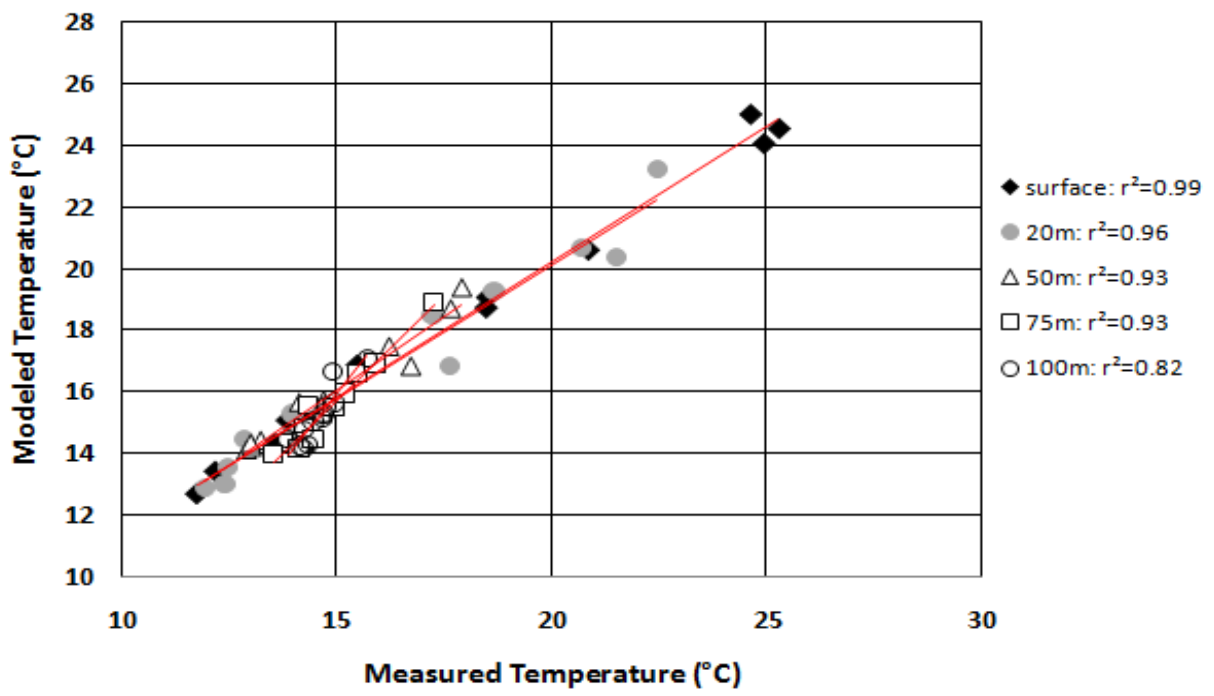

Figure 9(a) 


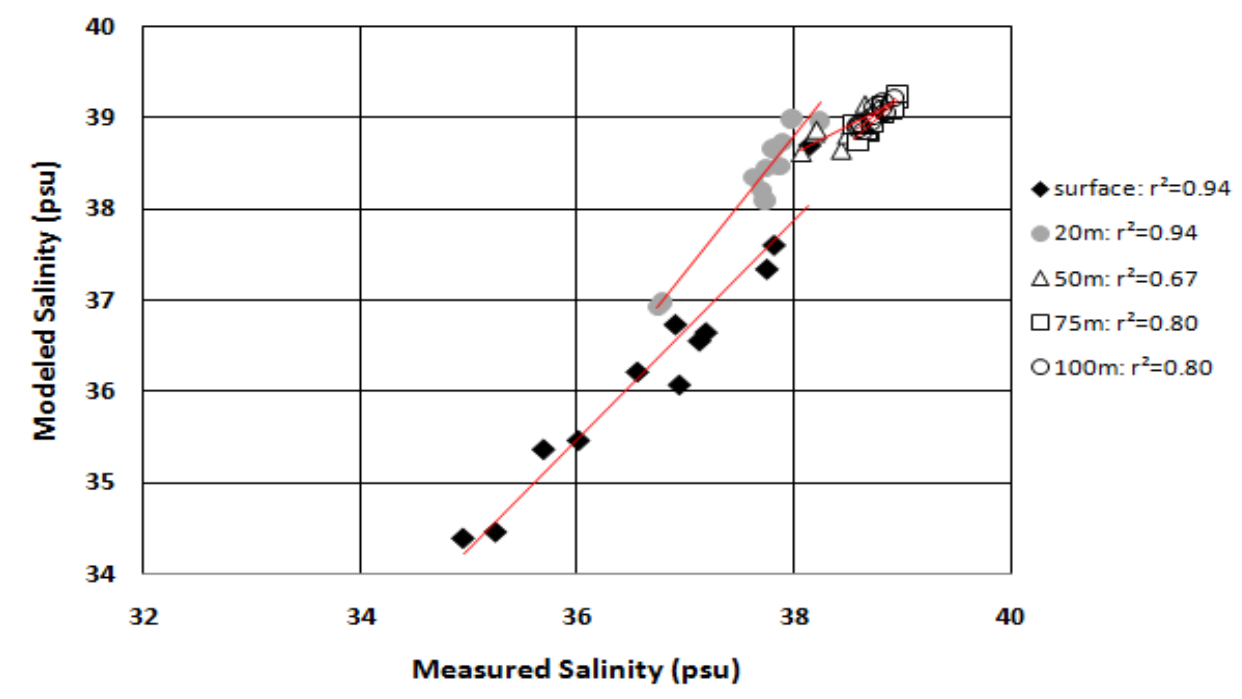

Figure 9(b)

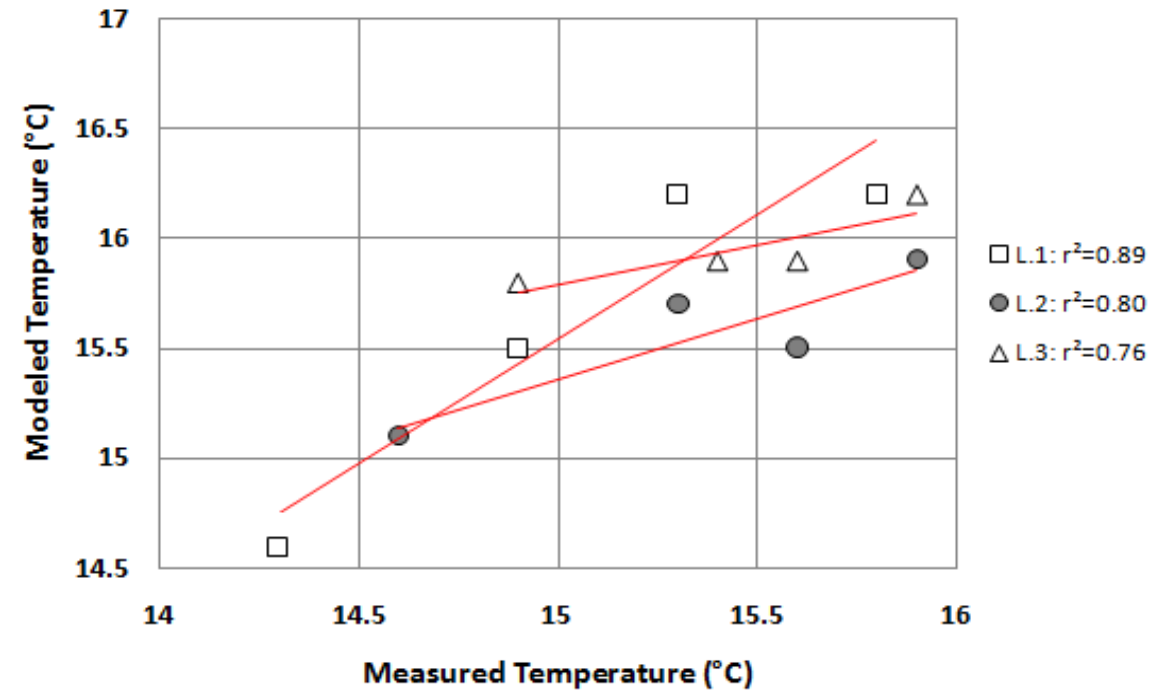

Figure 10(a)

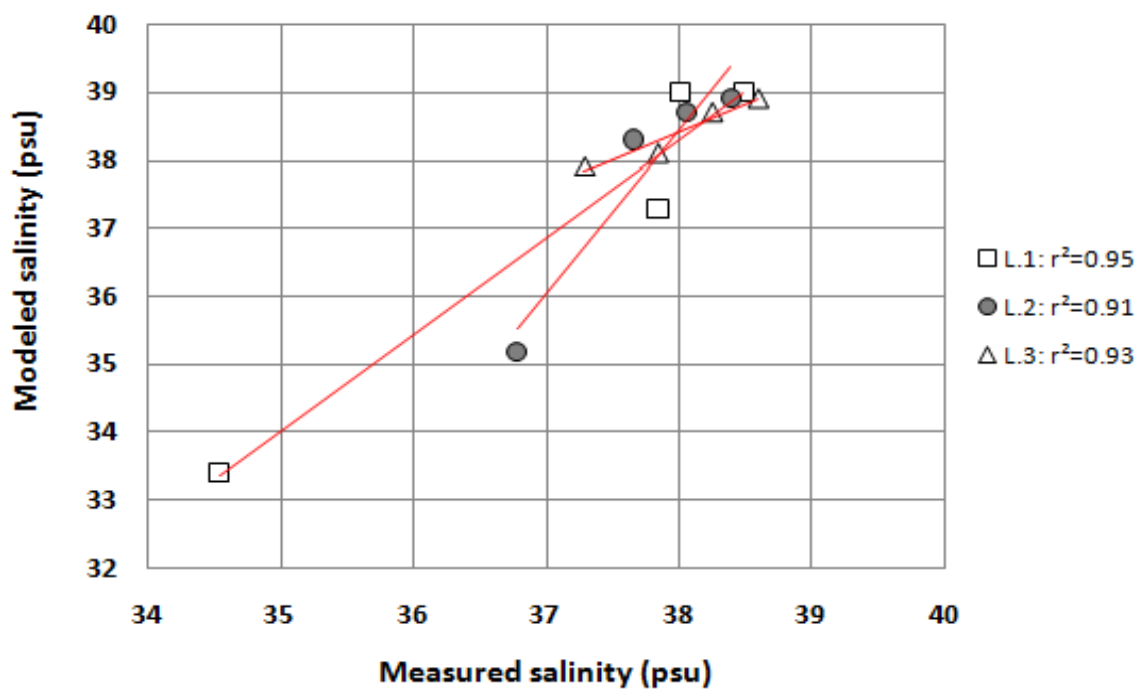

Figure 10(b) 


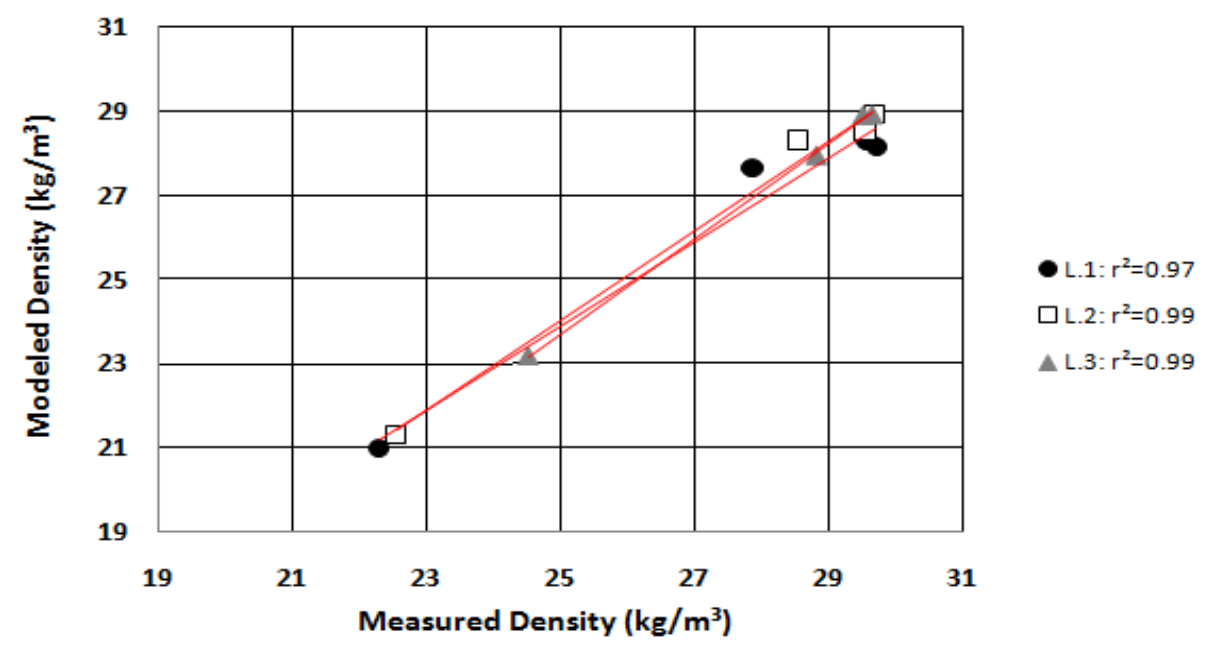

Figure 10(c)

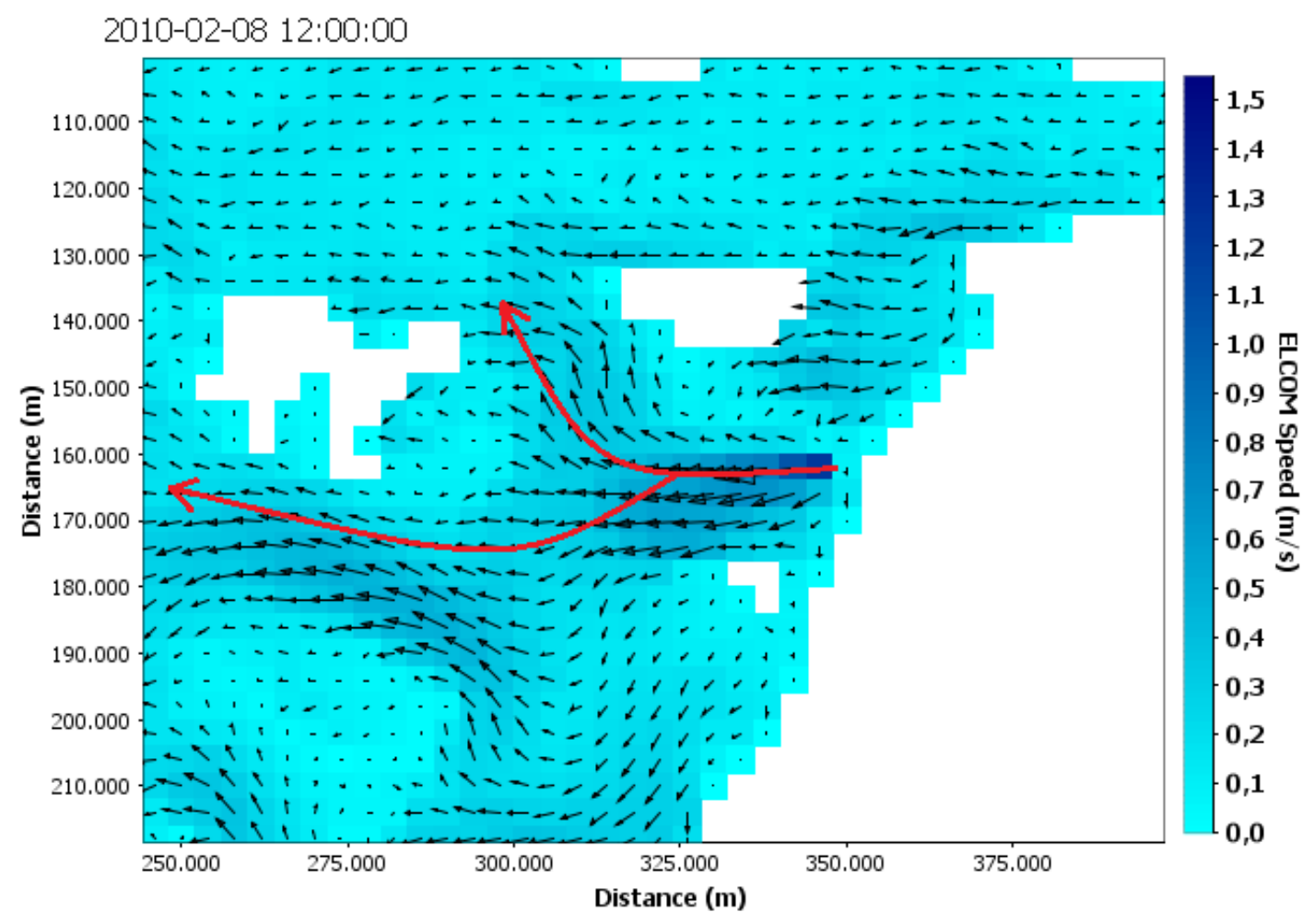

Figure 11(a) 
2010-05-13 00:00:00

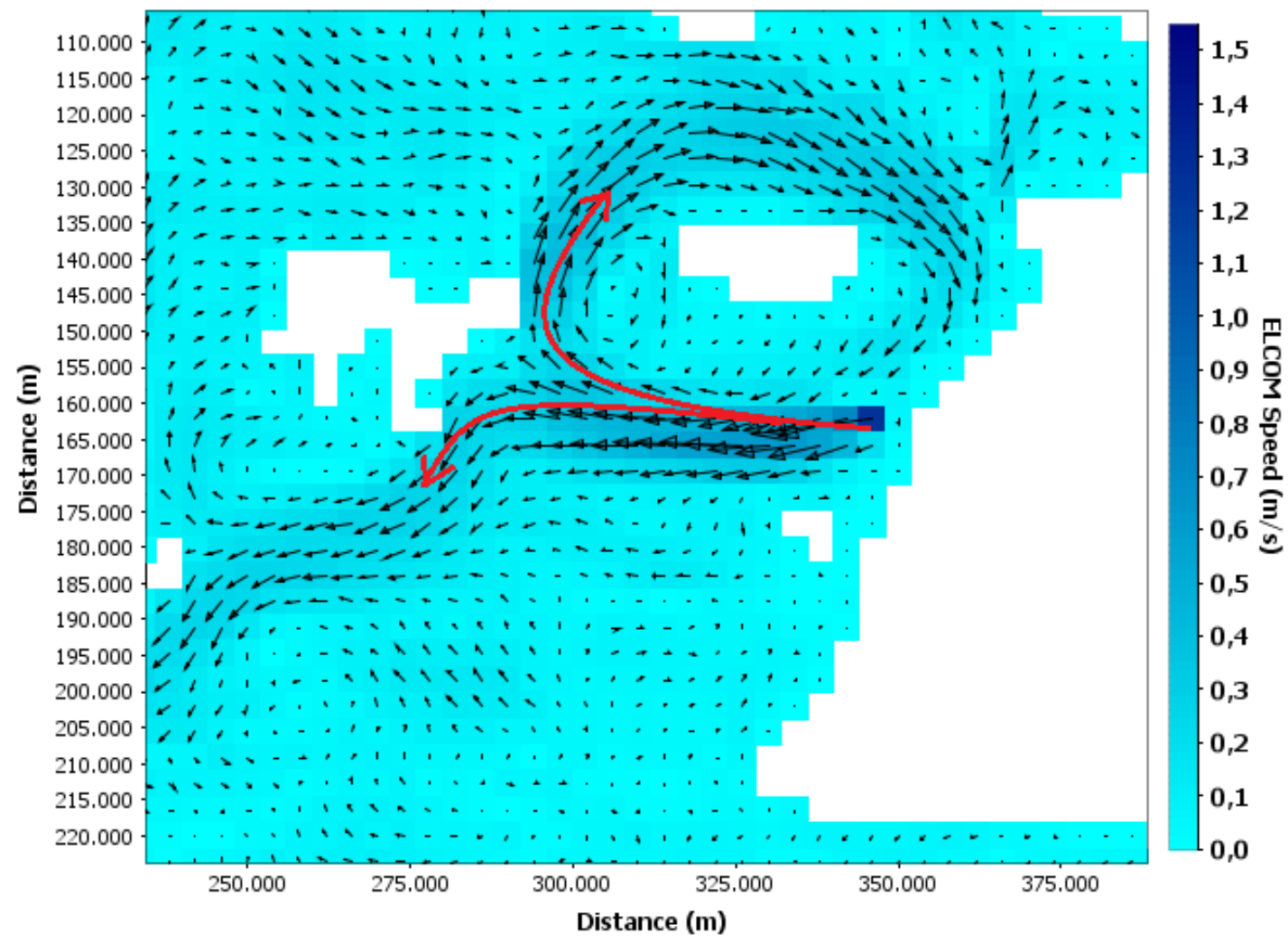

Figure 11(b)

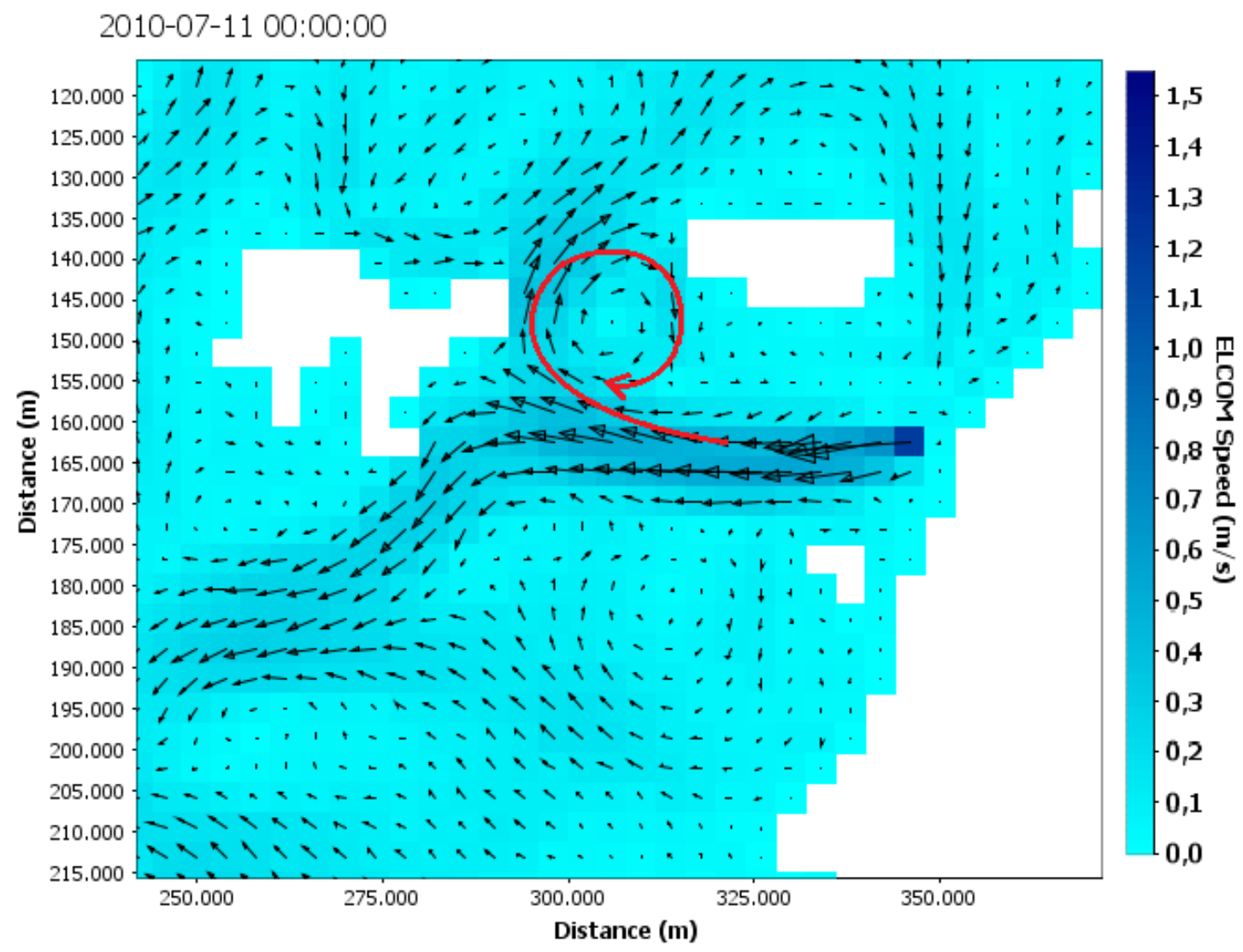

Figure 11(c) 


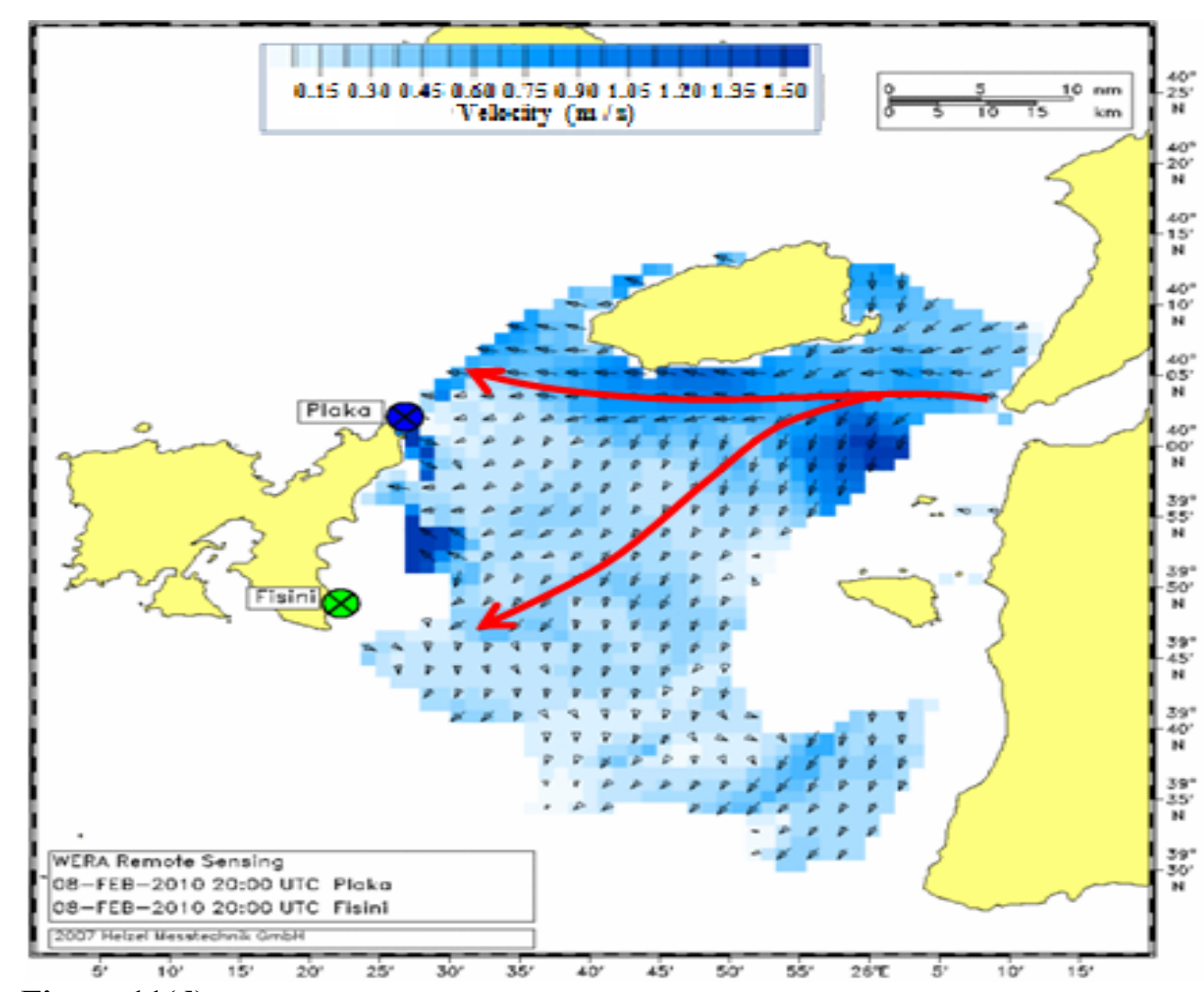

Figure 11(d)

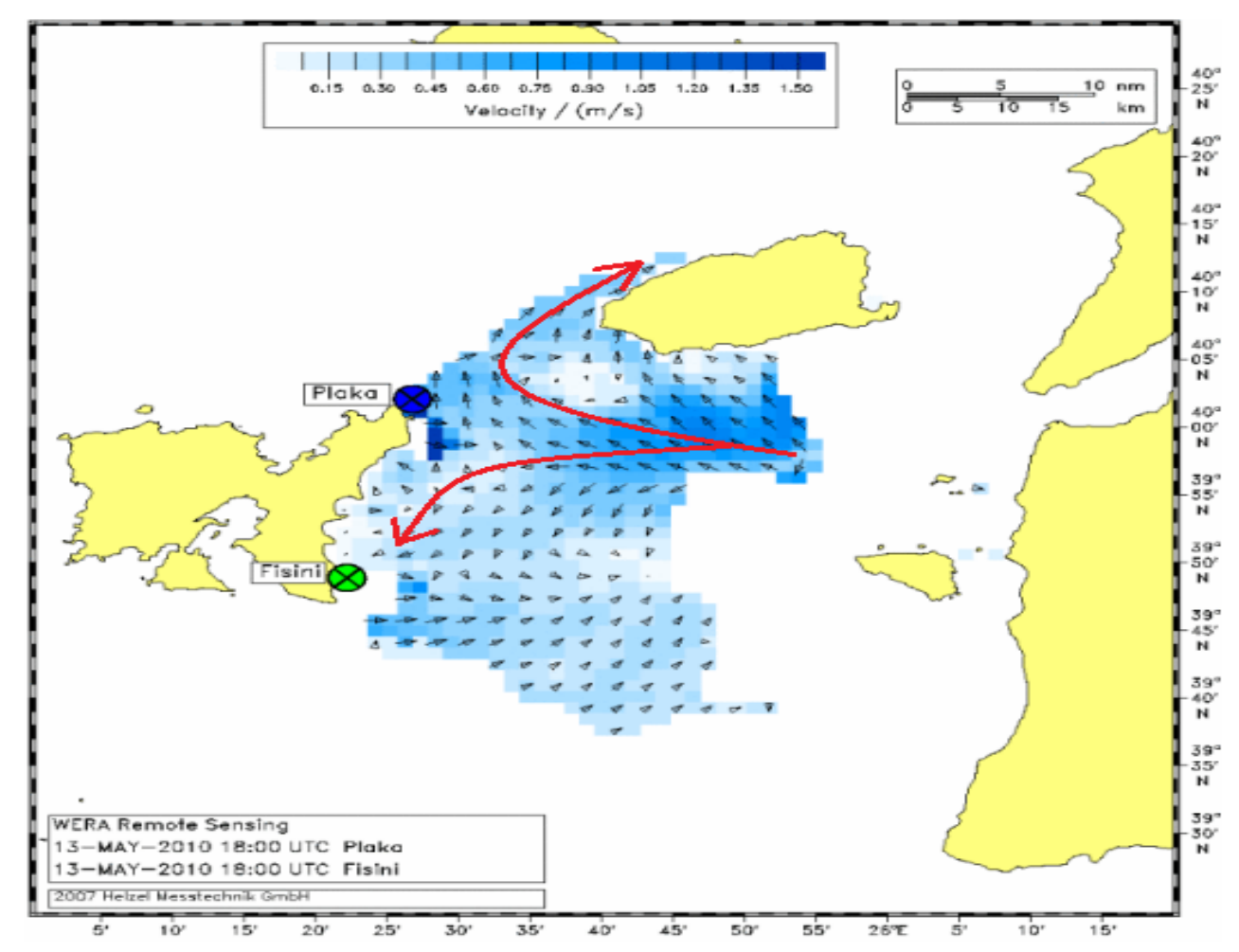

Figure 11(e) 


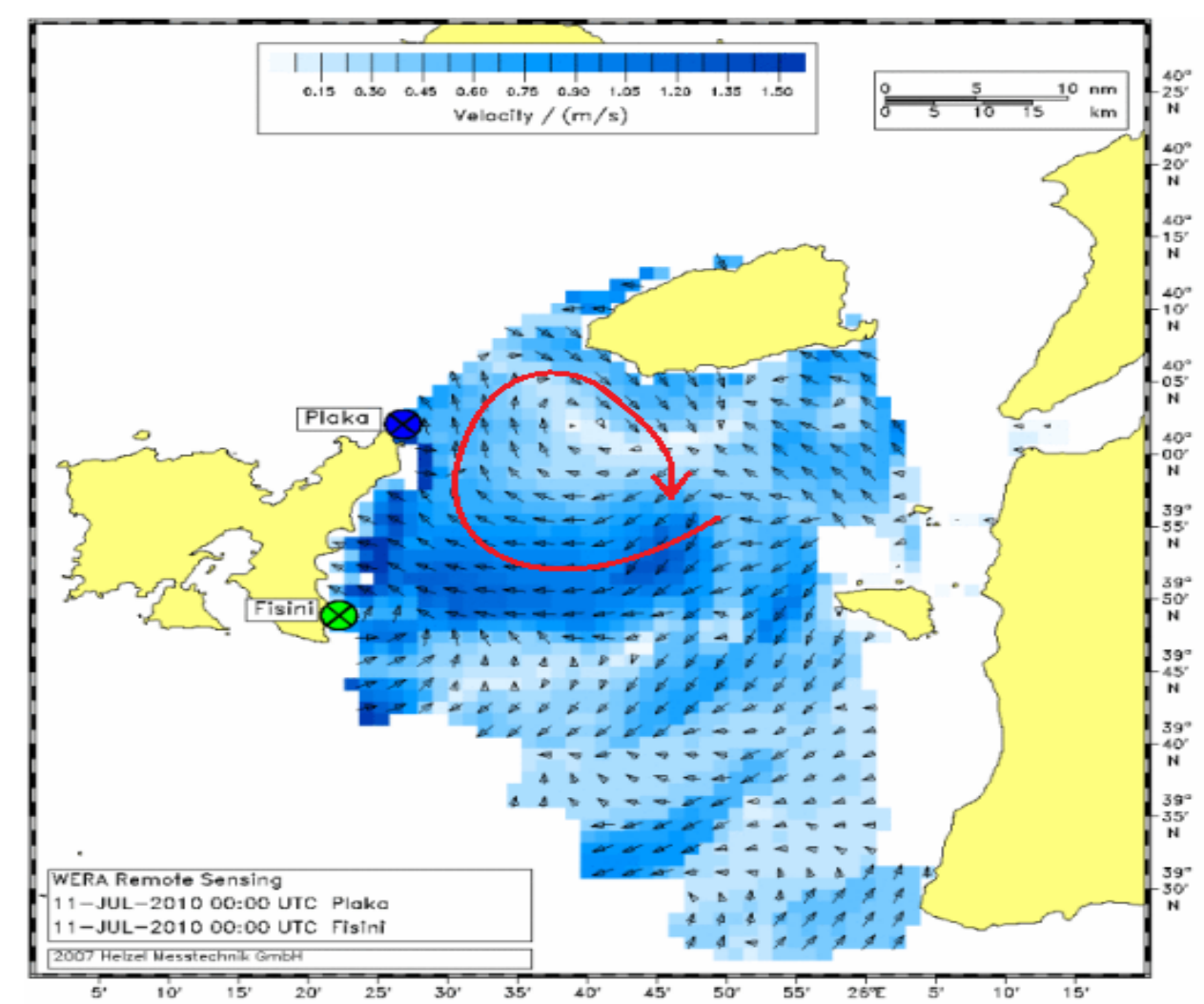

Figure 11(f)
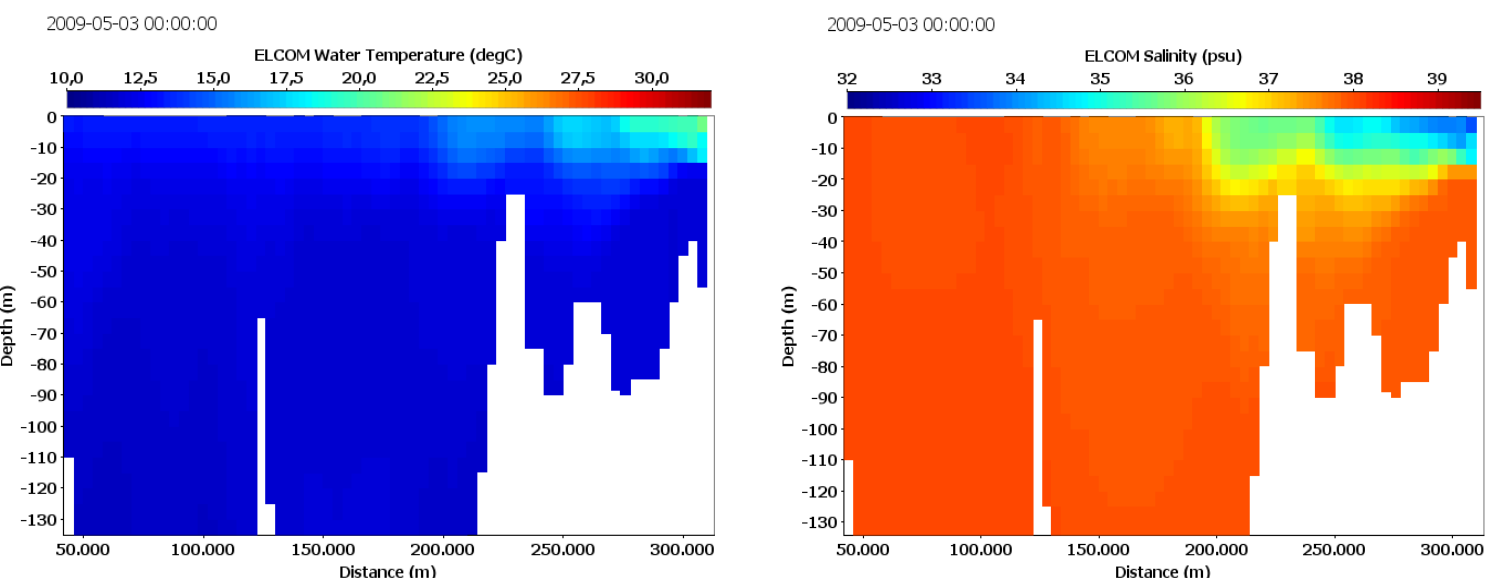

Figure 12(a)

Figure 12(b) 

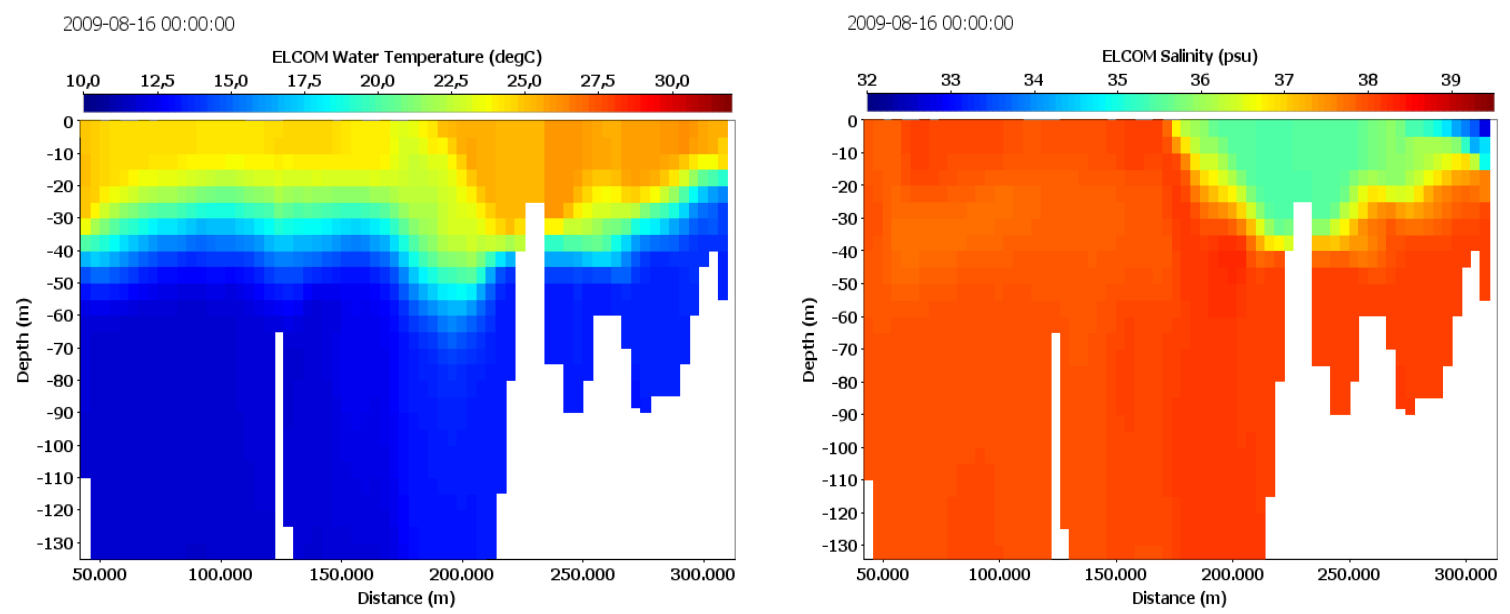

Figure 12(c)

Figure 12(d)
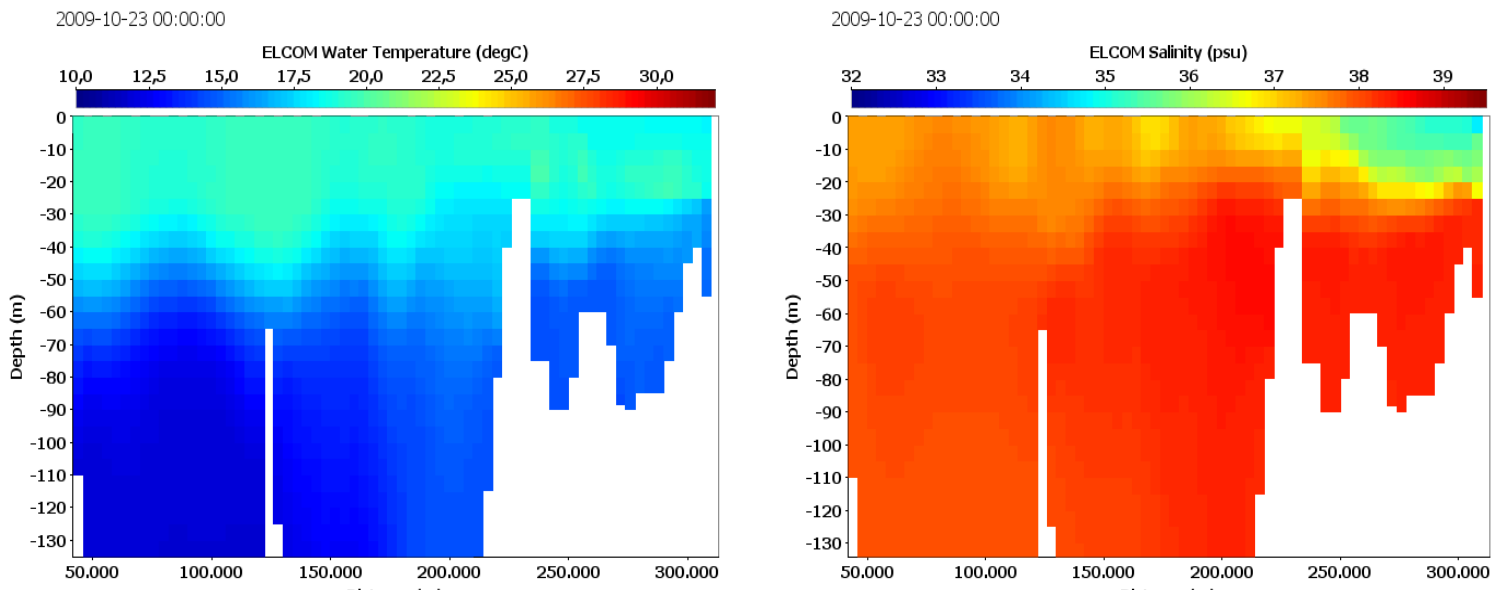

Figure 12(e)

Figure 12(f)

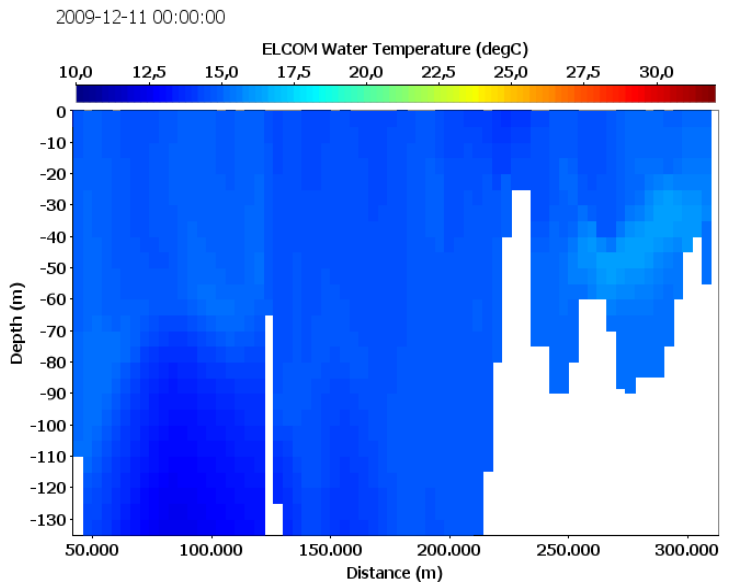

Figure 12(g)

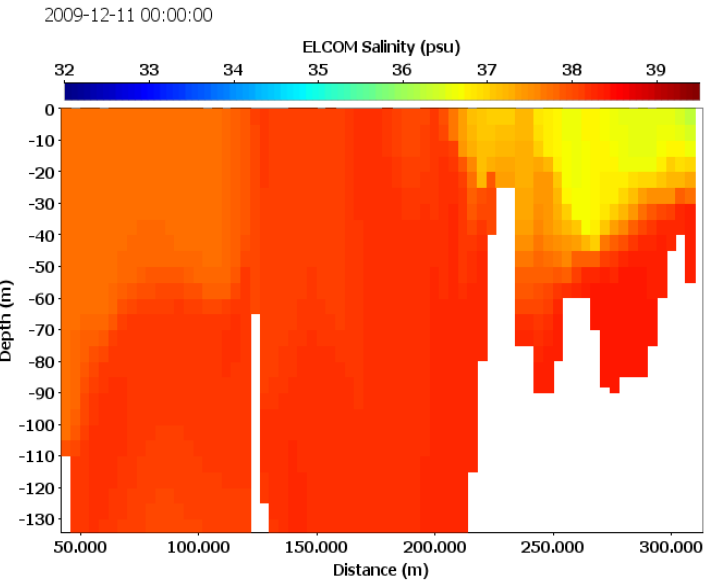

Figure 12(h) 


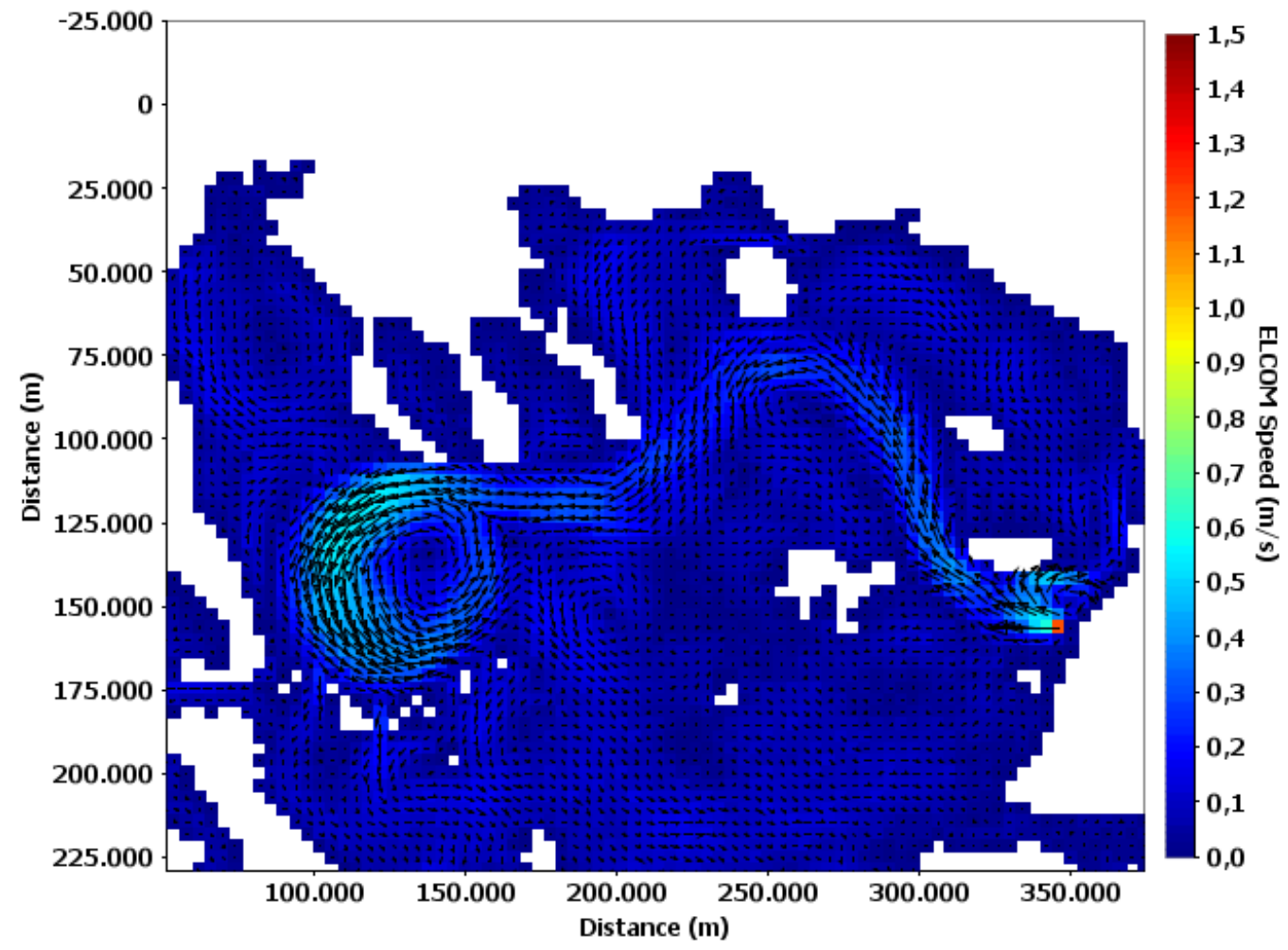

Figure 13(a)

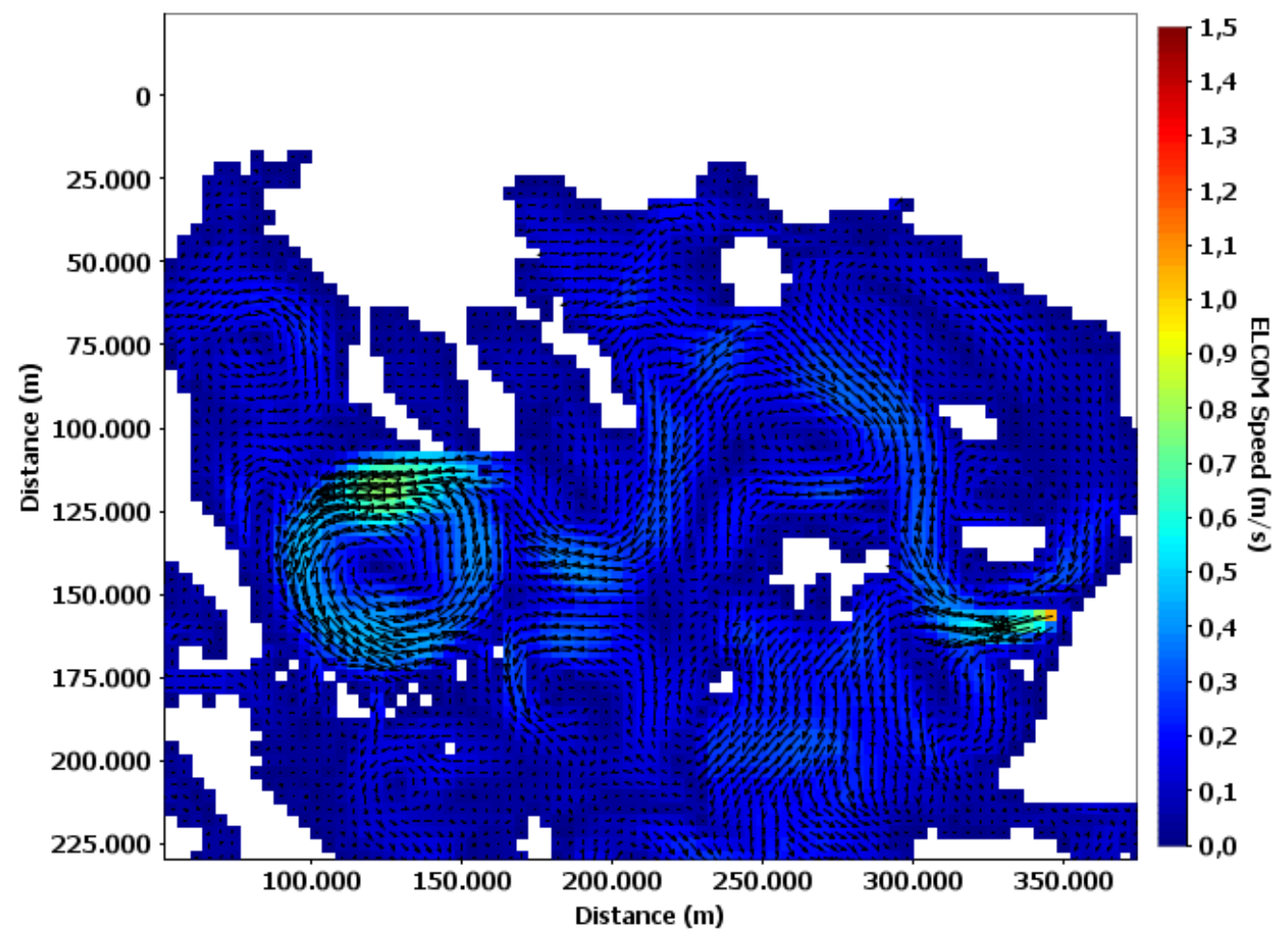

Figure 13(b) 


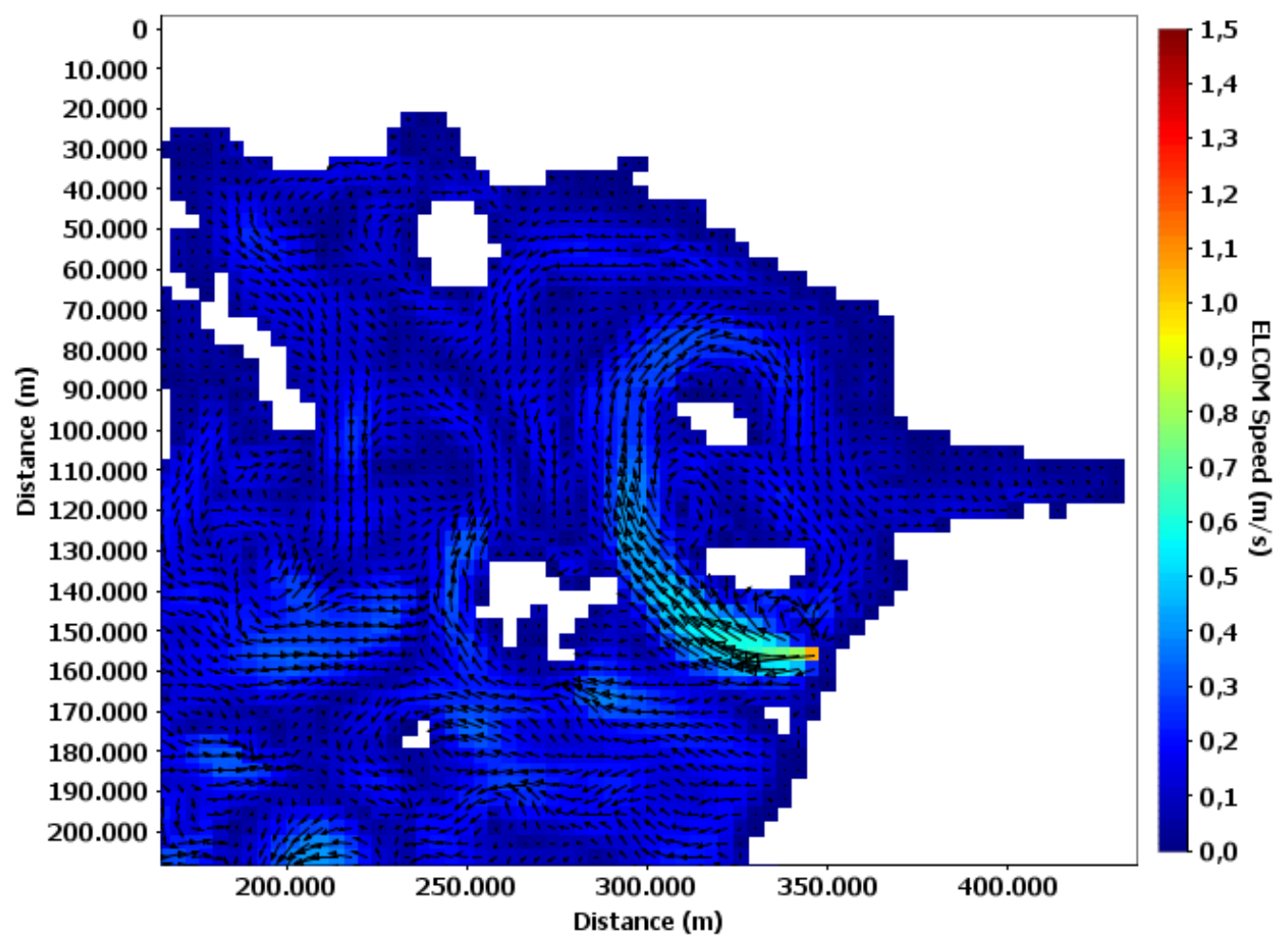

Figure 13(c)

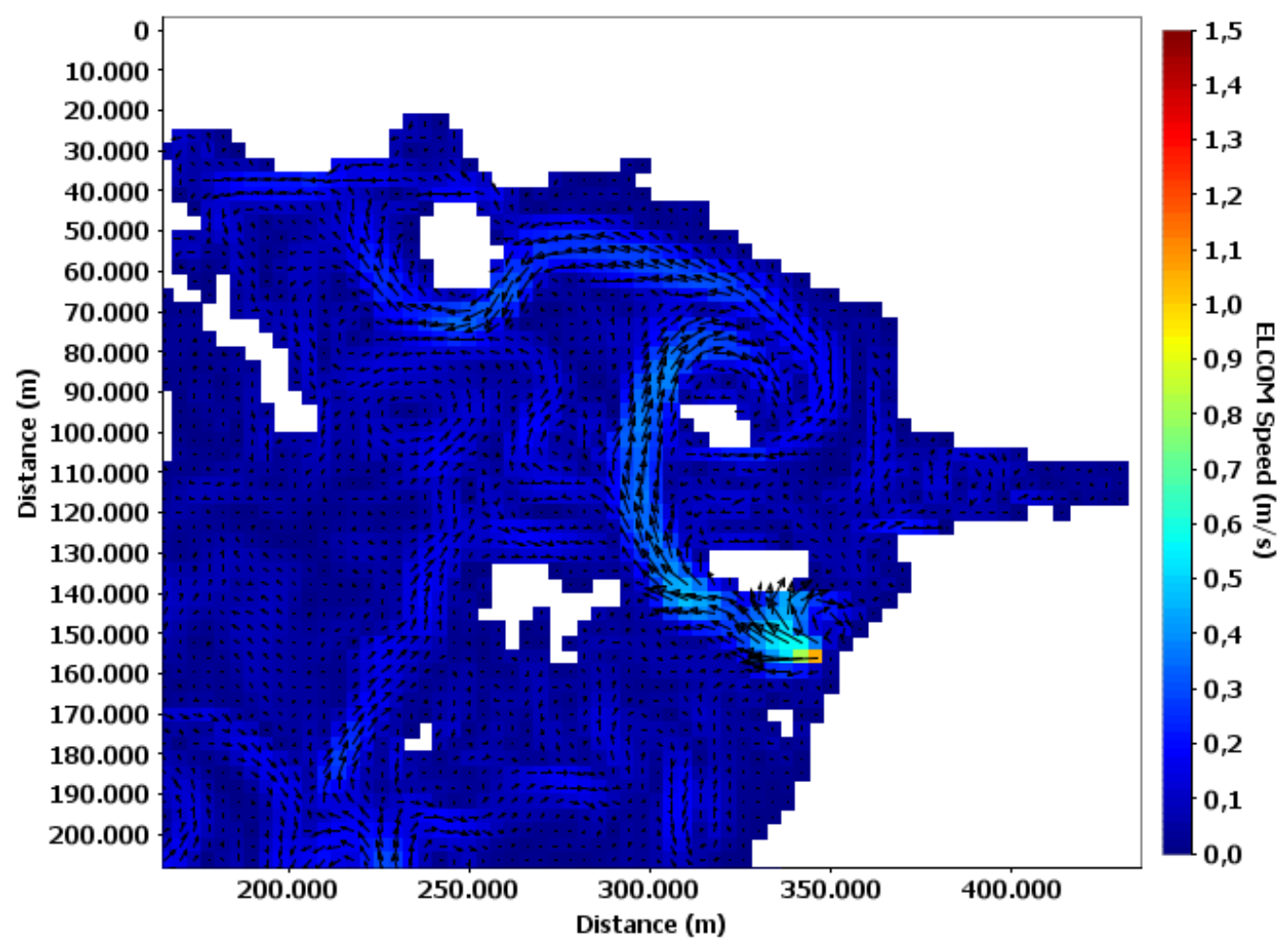

Figure 13(d) 


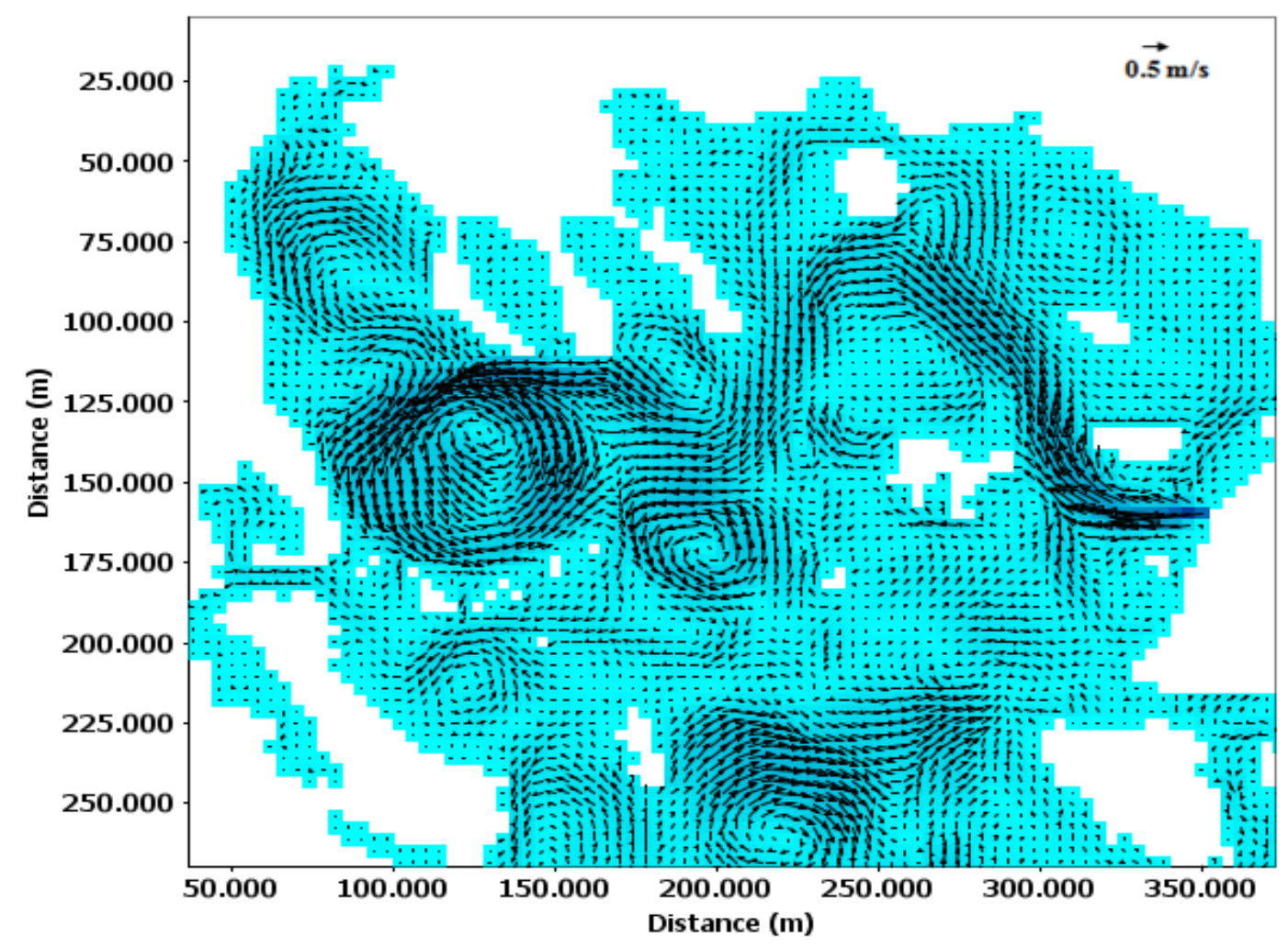

Figure 14(a)

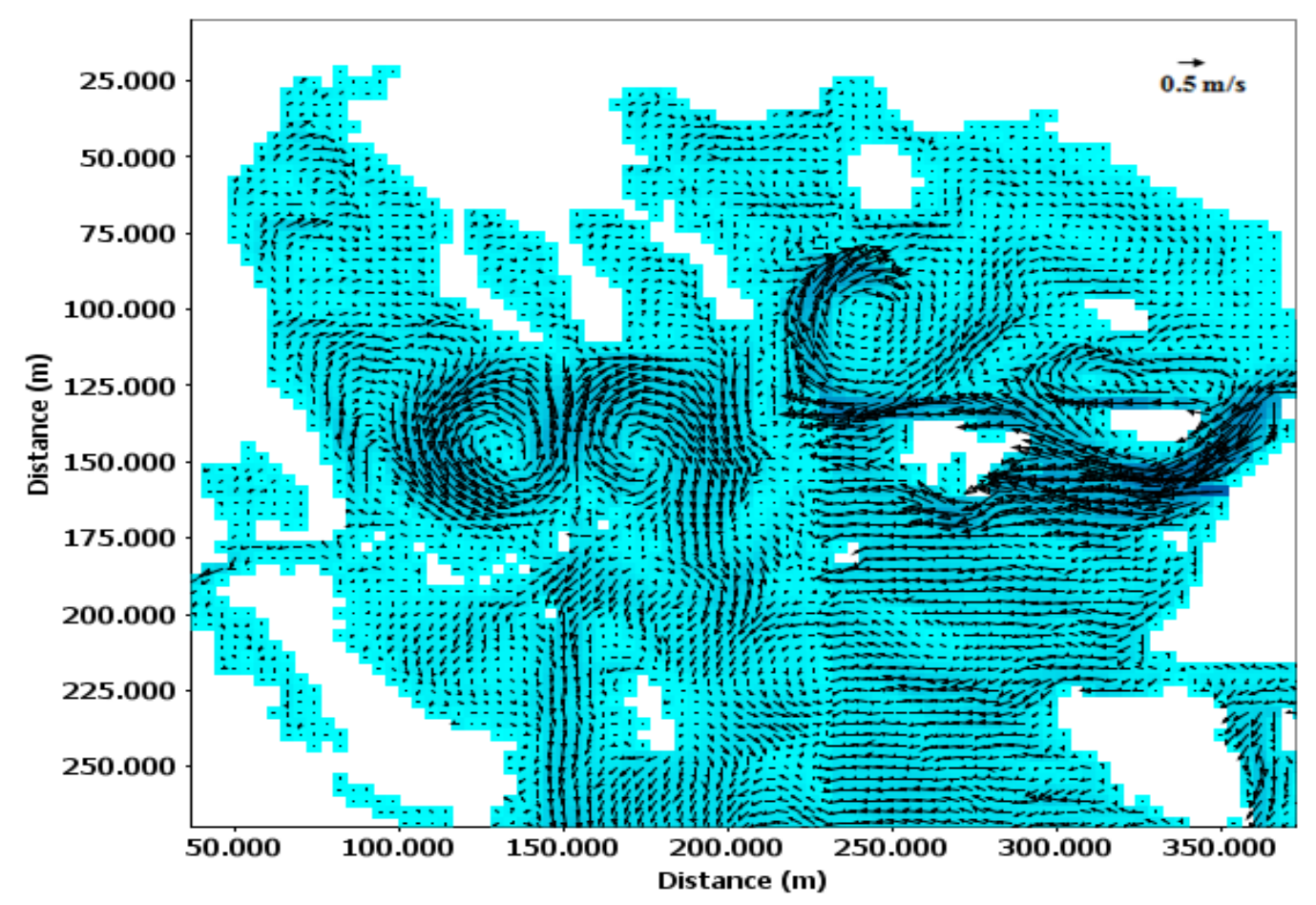

Figure 14(b) 


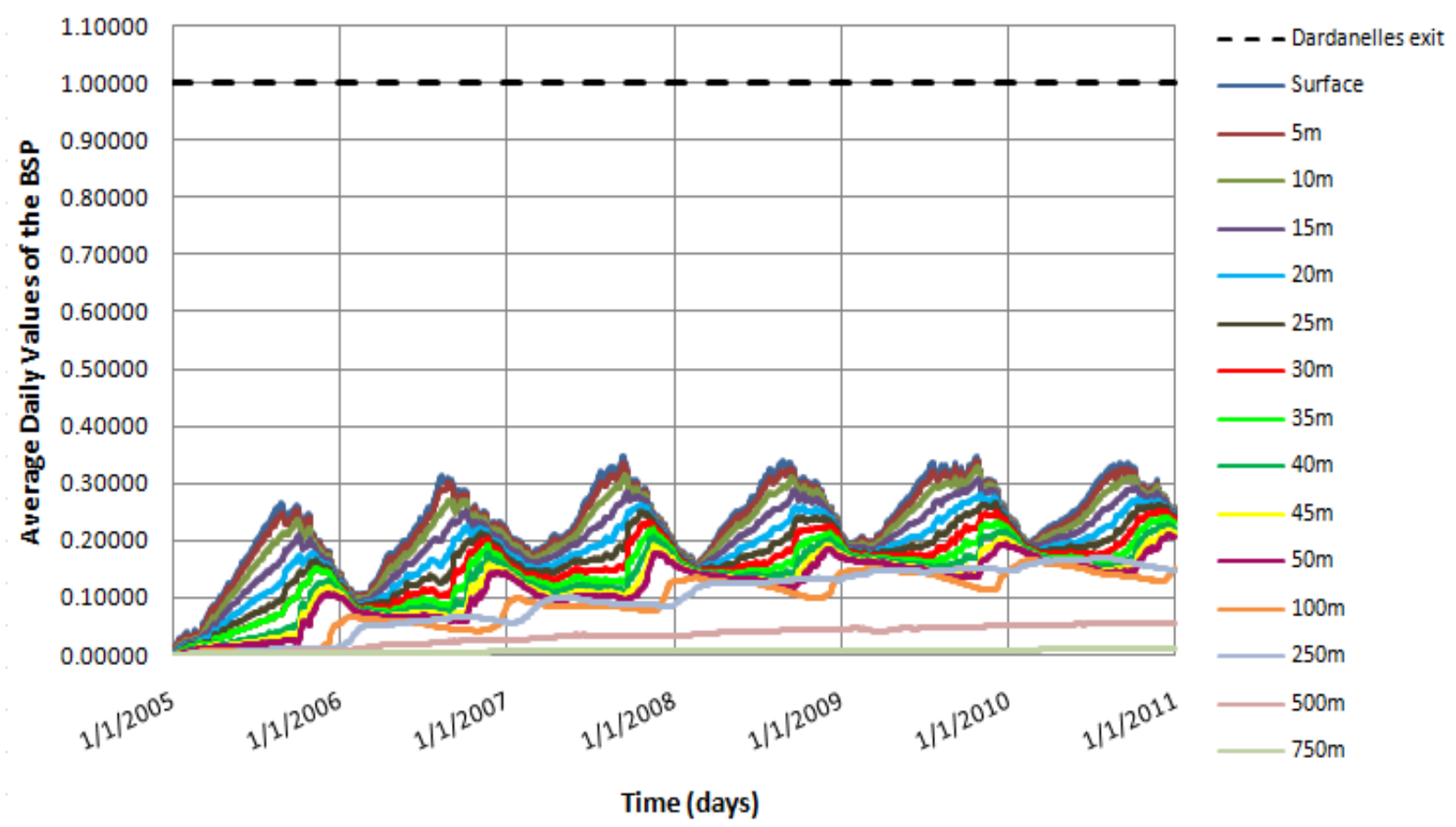

Figure 15
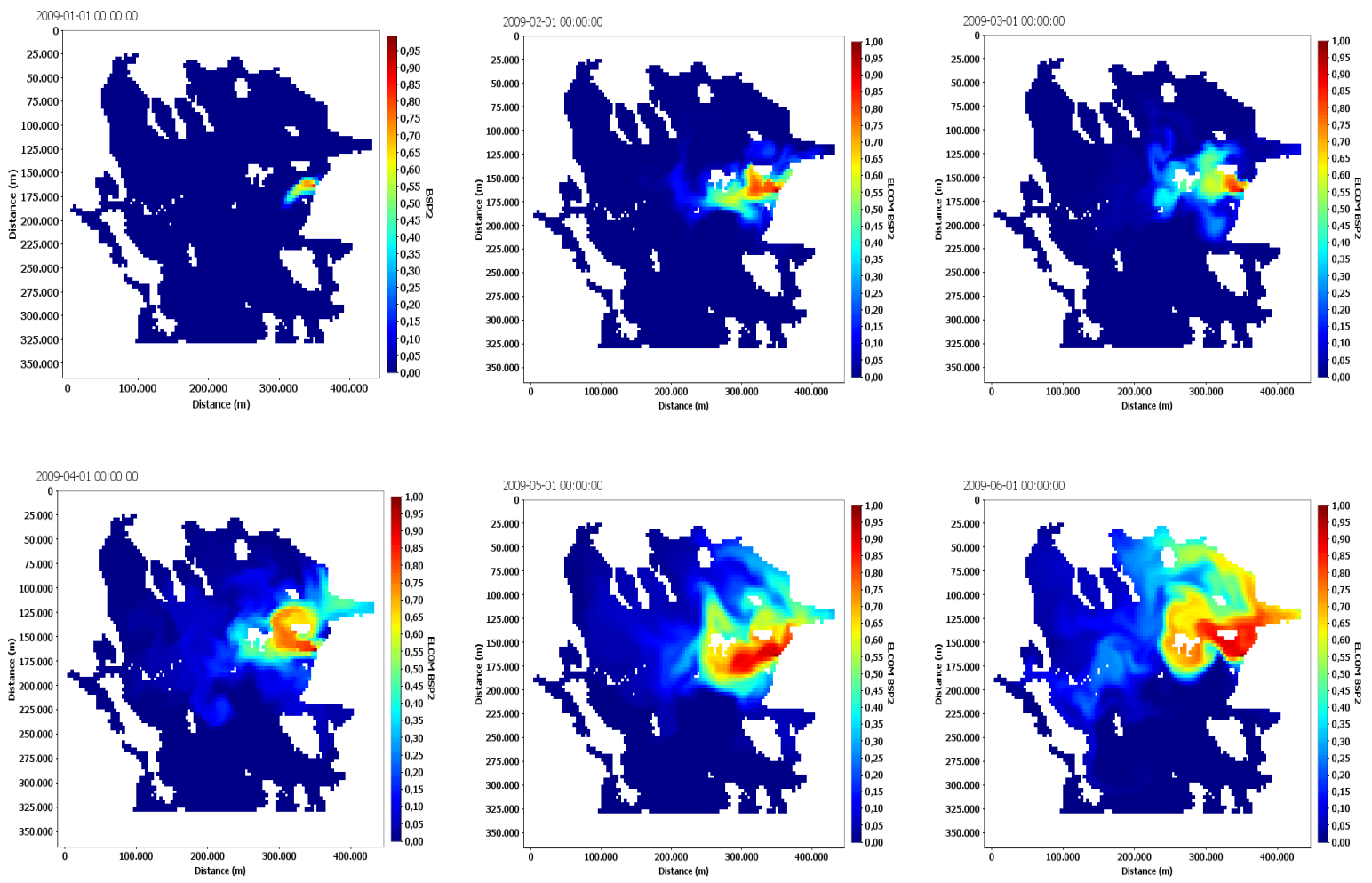

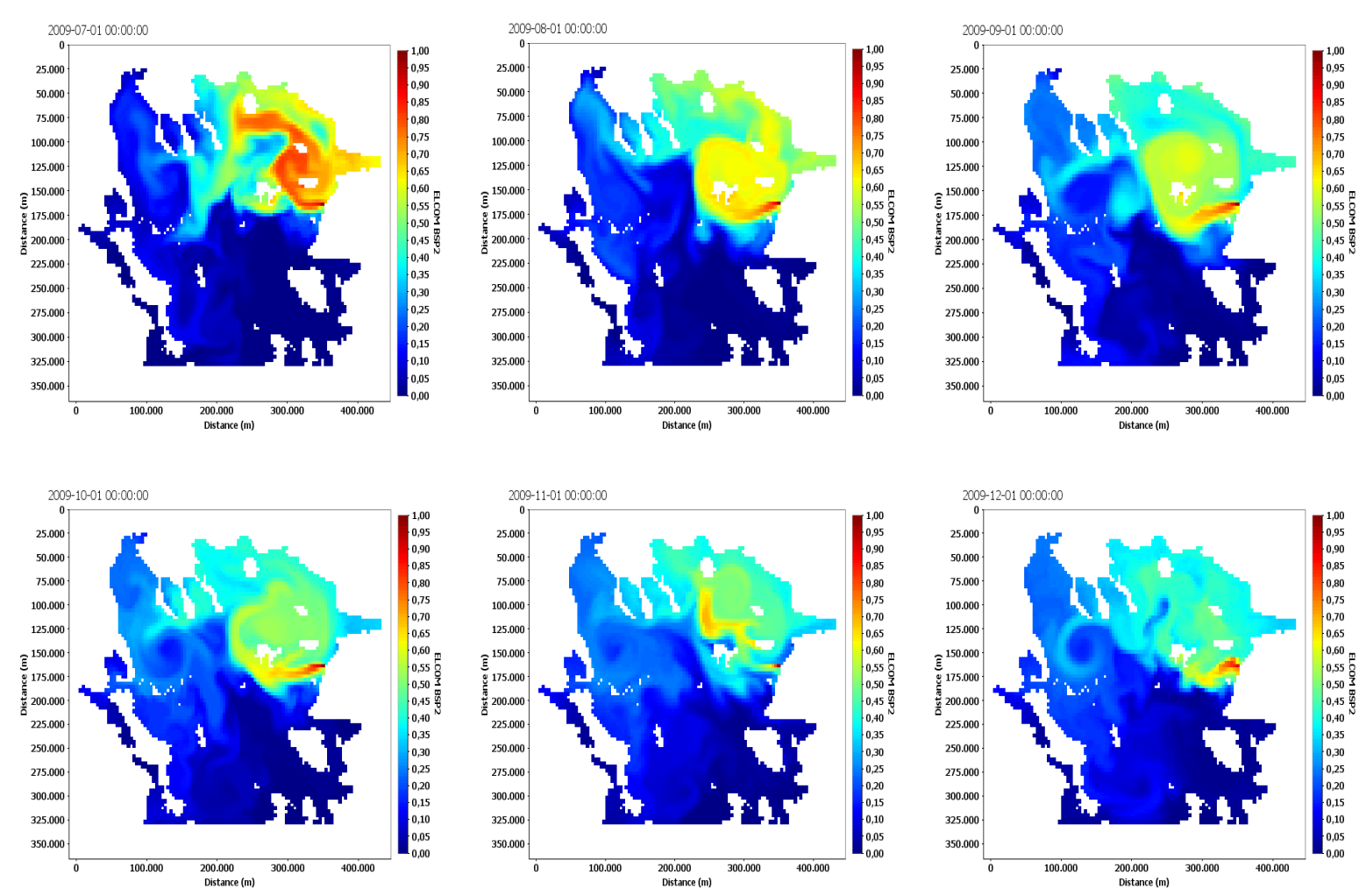

\section{Figure 16}

Table 1

\begin{tabular}{|c|c|c|}
\hline Model Components & Sub-components & Details \\
\hline \multirow[t]{7}{*}{$\begin{array}{l}\text { Computational grid } \\
\text { and set up }\end{array}$} & Grid Type & Plaid, Uniform \\
\hline & Cell size & $\begin{array}{l}4 \times 4 \mathrm{~km} \text { in the horizontal direction, } 5 \mathrm{~m} \text { in the vertical } \\
\text { direction }\end{array}$ \\
\hline & Total number of cells & 479349 cells \\
\hline & Land boundaries & Greece, Turkey \\
\hline & Open boundary & $\begin{array}{l}\text { Southern end of Northern Aegean Sea, adjacent to } \\
\text { Chios Island }\end{array}$ \\
\hline & Calculation time step & $3 \mathrm{~min}$ \\
\hline & Simulated real flow period & 1 January 2005 - 31 December 2010 \\
\hline \multirow[t]{3}{*}{ Forcing } & Meteorological & $\begin{array}{l}\text { Measured solar radiation, relative humidity, air } \\
\text { temperature and pressure, rainfall at Genisea station }\end{array}$ \\
\hline & & $\begin{array}{l}\text { North Greece. Measured wind speed and direction at } \\
\text { Genisea, Athos, Skyros Island, and Lesvos Island. }\end{array}$ \\
\hline & Open boundary & $\begin{array}{l}\text { Field data values for salinity and water temperature } \\
\text { from Mykonos stations (Hellenic Centre for Marine } \\
\text { Research 2010) }\end{array}$ \\
\hline Inflows & Dardanelles & $\begin{array}{l}\text { Average monthly discharge (Kanarska and } \\
\text { Maderich, 2008) }\end{array}$ \\
\hline Initial conditions & Temperature and salinity & Literature values (Kanarska and Maderich, 2008) \\
\hline \multirow[t]{2}{*}{$\begin{array}{l}\text { Calibration and } \\
\text { Validation }\end{array}$} & Temperature and salinity & $\begin{array}{l}\text { Field data (Hellenic Centre for Marine Research, } \\
\text { 2010, Evangeliou et al., 2009) }\end{array}$ \\
\hline & Circulation & $\begin{array}{l}\text { Field data (Hellenic Centre for Marine Research, } \\
\text { 2010) }\end{array}$ \\
\hline
\end{tabular}


Table 2

\begin{tabular}{|c|c|c|c|c|c|}
\hline Station & Co-ordinates & Depth (m) & Salinity (psu) & Temperature $\left({ }^{\circ} \mathrm{C}\right)$ & BSP* \\
\hline Athos & $\begin{array}{ll}39^{\circ} & 57.843 \mathrm{~N} \\
24^{\circ} & 43.208 \mathrm{E}\end{array}$ & $\begin{array}{l}5 \\
10 \\
20 \\
30 \\
40 \\
60\end{array}$ & $\begin{array}{l}37.7 \\
37.7 \\
37.9 \\
38.0 \\
38.1 \\
38.2\end{array}$ & $\begin{array}{l}14.4 \\
14.5 \\
14.7 \\
14.9 \\
15.3 \\
15.1\end{array}$ & $\begin{array}{l}0.25 \\
0.25 \\
0.23 \\
0.19 \\
0.16 \\
0.13\end{array}$ \\
\hline L.1 & $\begin{array}{l}40^{\circ} 04.22 \mathrm{~N} \\
25^{\circ} 30.08 \mathrm{E}\end{array}$ & $\begin{array}{l}5 \\
10 \\
20 \\
30 \\
40 \\
60\end{array}$ & $\begin{array}{l}37.1 \\
37.1 \\
37.2 \\
37.6 \\
38.0 \\
38.2\end{array}$ & $\begin{array}{l}14.6 \\
14.7 \\
14.9 \\
15.3 \\
15.6 \\
15.3\end{array}$ & $\begin{array}{l}0.45 \\
0.45 \\
0.42 \\
0.32 \\
0.19 \\
0.13\end{array}$ \\
\hline L.2 & $\begin{array}{l}39^{\circ} 52.06 \mathrm{~N} \\
25^{\circ} 39.16 \mathrm{E}\end{array}$ & $\begin{array}{l}5 \\
10 \\
20 \\
30 \\
40 \\
60\end{array}$ & $\begin{array}{l}36.8 \\
36.9 \\
37.0 \\
37.3 \\
37.7 \\
38.3\end{array}$ & $\begin{array}{l}14.5 \\
14.7 \\
15.1 \\
15.3 \\
15.6 \\
15.0\end{array}$ & $\begin{array}{l}0.55 \\
0.54 \\
0.47 \\
0.39 \\
0.28 \\
0.11\end{array}$ \\
\hline L.3 & $\begin{array}{l}39^{\circ} 48.18 \mathrm{~N} \\
25^{\circ} 39.21 \mathrm{E}\end{array}$ & $\begin{array}{l}5 \\
10 \\
20 \\
30 \\
40 \\
60\end{array}$ & $\begin{array}{l}36.9 \\
37.0 \\
37.1 \\
37.3 \\
37.8 \\
38.3\end{array}$ & $\begin{array}{l}14.8 \\
15.0 \\
15.1 \\
15.4 \\
15.5 \\
15.1\end{array}$ & $\begin{array}{l}0.53 \\
0.51 \\
0.32 \\
0.21 \\
0.15 \\
0.11\end{array}$ \\
\hline
\end{tabular}

* The BSP concentration is dimensionless with values varying from 0 to 1 . 
Table 3

\begin{tabular}{|c|c|c|c|c|c|}
\hline Station & Co-ordinates & Depth (m) & Salinity (psu) & Temperature $\left({ }^{\circ} \mathrm{C}\right)$ & BSP* \\
\hline Athos & $\begin{array}{l}39^{\circ} 57.843 \mathrm{~N} \\
24^{\circ} 43.208 \mathrm{E}\end{array}$ & $\begin{array}{l}5 \\
10 \\
20 \\
30 \\
40 \\
60\end{array}$ & $\begin{array}{l}37.6 \\
37.6 \\
37.7 \\
37.8 \\
37.8 \\
37.9\end{array}$ & $\begin{array}{l}20.2 \\
18.1 \\
15.8 \\
14.3 \\
13.5 \\
13.7\end{array}$ & $\begin{array}{l}0.14 \\
0.14 \\
0.13 \\
0.14 \\
0.14 \\
0.14\end{array}$ \\
\hline L. 1 & $\begin{array}{l}40^{\circ} 04.22 \mathrm{~N} \\
25^{\circ} 30.08 \mathrm{E}\end{array}$ & $\begin{array}{l}5 \\
10 \\
20 \\
30 \\
40 \\
60\end{array}$ & $\begin{array}{l}36.0 \\
37.1 \\
37.8 \\
37.8 \\
37.9 \\
37.9\end{array}$ & $\begin{array}{l}19.6 \\
17.9 \\
15.0 \\
13.9 \\
13.0 \\
12.9\end{array}$ & $\begin{array}{l}0.44 \\
0.27 \\
0.16 \\
0.14 \\
0.13 \\
0.13\end{array}$ \\
\hline L. 2 & $\begin{array}{l}39^{\circ} 52.06 \mathrm{~N} \\
25^{\circ} 39.16 \mathrm{E}\end{array}$ & $\begin{array}{l}5 \\
10 \\
20 \\
30 \\
40 \\
60\end{array}$ & $\begin{array}{l}37.6 \\
37.8 \\
37.8 \\
37.8 \\
37.9 \\
37.9\end{array}$ & $\begin{array}{l}20.5 \\
17.8 \\
15.1 \\
13.9 \\
12.9 \\
12.8\end{array}$ & $\begin{array}{l}0.16 \\
0.13 \\
0.12 \\
0.12 \\
0.12 \\
0.12\end{array}$ \\
\hline L.3 & $\begin{array}{l}39^{\circ} 48.18 \mathrm{~N} \\
25^{\circ} 39.21 \mathrm{E}\end{array}$ & $\begin{array}{l}5 \\
10 \\
20 \\
30 \\
40 \\
60\end{array}$ & $\begin{array}{l}37.8 \\
37.8 \\
37.8 \\
37.8 \\
37.9 \\
37.9 \\
\end{array}$ & $\begin{array}{l}20.1 \\
18.0 \\
15.1 \\
13.8 \\
12.8 \\
12.9 \\
\end{array}$ & $\begin{array}{l}0.14 \\
0.12 \\
0.11 \\
0.12 \\
0.12 \\
0.12 \\
\end{array}$ \\
\hline
\end{tabular}

* The BSP concentration is dimensionless with values varying from 0 to 1 . 